\title{
Self-limiting Nitrogen/Hydrogen Plasma Radical Chemistry in \\ Plasma-Enhanced Atomic Layer Deposition of Cobalt
}

\author{
Ji Liu ${ }^{\mathrm{a}}$, Hongliang Lu ${ }^{\mathrm{b}}$, David Wei Zhang ${ }^{\mathrm{b}}$, and Michael Nolan ${ }^{\mathrm{a},{ }^{*}}$ \\ ${ }^{a}$ Tyndall National Institute, University College Cork, Lee Maltings, Dyke Parade, Cork, T12 \\ R5CP, Ireland \\ b State Key Laboratory of ASIC and System, Shanghai Institute of Intelligent Electronics \& \\ Systems, School of Microelectronics, Fudan University, Shanghai 200433, China
}

Corresponding author:

*E-mail: Michael.nolan@tyndall.ie. Tel: +353 0212346983 
Graphic abstract

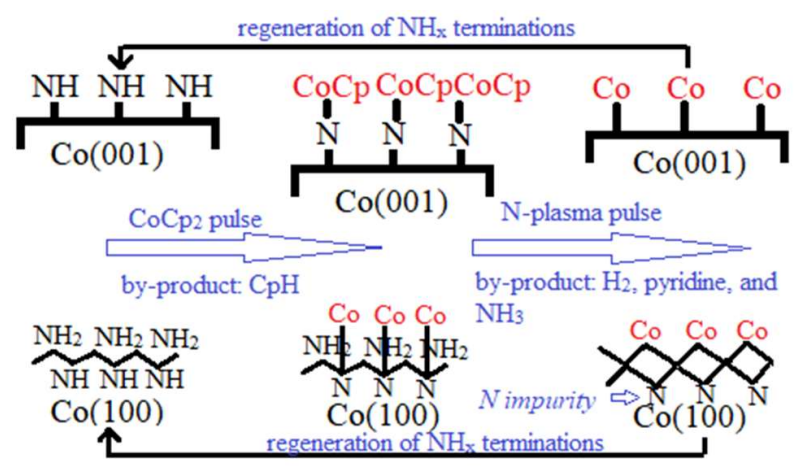

Abstract

Cobalt (Co) is a potential candidate in replacing copper for interconnects and has been applied in the trenches in semiconductor industry over twenty years. A non-oxidizing reactant is required in plasma-enhanced atomic layer deposition (PE-ALD) of thin films of metals to avoid Ocontamination. PE-ALD of Co has been demonstrated experimentally with plasma sources of $\mathrm{NH}_{3}$ or a mixture of $\mathrm{N}_{2}$ and $\mathrm{H}_{2}$, but the growth mechanism and key reactions are not clear. In this paper, we have investigated the reactions of plasma generated radicals $\mathrm{H}, \mathrm{N}, \mathrm{NH}$ and $\mathrm{NH}_{2}$ at metal precursor $\left(\mathrm{CoCp}_{2}\right)$ terminated $\mathrm{Co}(001)$ and (100) surfaces using static DFT calculations at $0 \mathrm{~K}$ and molecular dynamics simulations at $600 \mathrm{~K} . \mathrm{N}$ radicals play an important role in eliminating surface-bound $\mathrm{Cp}$ ligand (if any) via pyridine $\left(\mathrm{C}_{5} \mathrm{H}_{5} \mathrm{~N}\right)$ formation and desorption, whereas $\mathrm{H}$ radicals have endothermic reactions for eliminating $\mathrm{Cp}$ ligand via $\mathrm{CpH}$ formation and desorption. The surface $\mathrm{NH}_{\mathrm{x}}$ species are eliminated by $\mathrm{H}$ radicals via $\mathrm{NH}_{3}$ formation and desorption. The simulations of these key reactions show that on $\operatorname{Co}(001)$ surface, the remaining $\mathrm{Cp}$ ligand and surface $\mathrm{NH}_{\mathrm{x}}$ species after the metal precursor pulse will be completely removed with $\mathrm{N}$ and $\mathrm{H}$ radicals, resulting in Co atoms deposited on $\mathrm{Co}(001)$ surface at a coverage of $3.03 \mathrm{Co} / \mathrm{nm}^{2}$. Whereas, on $\mathrm{Co}(100)$ surface, the surface $\mathrm{NH}_{2}$ species cannot be completely removed via $\mathrm{NH}_{3}$ 
formation and desorption due to overall endothermic reactions. Instead, $\mathrm{H}$ radicals react with trench $\mathrm{N}$ species, contributed to $\mathrm{H}$ transfer at metal precursor pulse, to form $\mathrm{NH}$. These trench $\mathrm{N}$ species cannot be eliminated completely on $\mathrm{Co}(100)$ surface, which will be the source of $\mathrm{N}$ impurities for the deposited Co thin films. At the post-plasma stage, the metal surface will be covered with $\mathrm{NH}_{\mathrm{x}}$-terminations with plasma generated $\mathrm{NH}$ radicals, which is then ready for the next deposition cycle. Our results explain why ammonia or $\mathrm{H}_{2} / \mathrm{N}_{2}$ plasma, which produce $\mathrm{NH}_{\mathrm{x}}$ species are required to deposit Co thin films using Co metallocene precursors.

\section{Introduction}

Copper $(\mathrm{Cu})$ has been used in the semiconductor industry as the interconnect material for over 20 years. ${ }^{1}$ However, the continuous deposition of conducting $\mathrm{Cu}$ films in the small and complex structures of present and future nanoelectronic device structures is, and will become more difficult. Copper requires a liner or seed layer to promote continuous film deposition. This layer is in addition to the barrier layer, which prevents the diffusion of $\mathrm{Cu}$ into the dielectric layer and $\mathrm{Si}$ substrates. ${ }^{2}$ As device dimensions shrink and more complex structures emerge, the volume available for copper interconnects at the transistor levels becomes correspondingly smaller and must accommodate the barrier, the liner and copper.

From a more general perspective, it is well known that at the nanoscale, $\mathrm{Cu}$ will preferentially aggregate into high resistivity $3 \mathrm{D}$ island structures. ${ }^{3-4}$ One solution to these issues is to replace copper with alternative metals that do not suffer from these issues. In this regard, the early transition metal Cobalt $(\mathrm{Co})$ is of high interest as alternative material for replacing $\mathrm{Cu}$ in next 
generation interconnects. Co has already been used in the trenches and vias with the downsizing of semiconductor devices. ${ }^{5-7}$

Finding suitable barrier/liner layers and combining these properties into one material is an outstanding challenge because the volume available in trenches and vias exacerbate the issues with copper, so a smaller volume occupied by the barrier and liner layer will help. However, it is clear that copper will ultimately be replaced by another metal.

There is also the question of the deposition of interconnect metals, in particular into high aspect ratio structures in nano-devices, where different surface facets are present and standard physical vapour deposition (PVD) will not give sufficient conformality and uniformity in these structures. Atomic layer deposition (ALD) is widely applied for conformal and uniform deposition offering a high degree of control over deposition at the atomic level, which is required for metal deposition onto high aspect ratio structures. ${ }^{8-9}$ Generally, ALD consists of two self-limiting half cycles, where the reactions will stop after all available surface sites are consumed and repeated cycling through the two half reactions allows a fine level of control over the thickness and conformality of the deposited film. In addition to the successful application of ALD in microelectronics and semiconductor industry, it is seeing exciting applications in the areas of catalysis and energy conversion and storage. ${ }^{6,10-11}$

For the ALD of Co metal, cyclopentadienyl $(\mathrm{Cp})$ based precursors such as the $\mathrm{CoCp}_{2}$ metallocene, $\mathrm{CoCp}(\mathrm{CO})_{2}$ and $\mathrm{Co}(\mathrm{CpAMD})$ have been used in thermal and plasma-enhanced ALD. ${ }^{12-13}$ For thermal ALD of Co with metal acetamidinates and hydrogen, the required growth temperature can be as high as $350^{\circ} \mathrm{C}$, while the growth rate can be as low as $0.12 \AA$ /cycle. ${ }^{14}$ With the application of plasma-enhanced ALD (PE-ALD) using $\mathrm{NH}_{3}$ plasma, the Co PE-ALD process window is between $200^{\circ} \mathrm{C}$ and $250^{\circ} \mathrm{C}$, with a reported growth rate of $0.5 \AA /$ cycle..$^{15}$ The reported growth per 
cycle with dicobalt octacarbonyl $\left(\mathrm{Co}_{2}(\mathrm{CO})_{8}\right)$ and $\mathrm{H}_{2}$ plasma is increased to $1.2 \AA$ /cycle in the ALD window of $75^{\circ} \mathrm{C}$ to $110^{\circ} \mathrm{C} .{ }^{16} \mathrm{Co}$ metal precursor $\mathrm{CoCp}(\mathrm{CO})_{2}$ has an even larger reported $\mathrm{GPC}$ at $1.5 \AA /$ cycle using $\mathrm{NH}_{3}$ plasma at a higher temperature of $300^{\circ} \mathrm{C} .{ }^{17}$

The reaction mechanism of film growth with ALD using an oxidizing reactant such as $\mathrm{O}_{3}$ and $\mathrm{H}_{2} \mathrm{O}$ is well-established. ${ }^{18-21}$ However, when depositing metals, an O-source will promote oxidation of the metal and therefore cause contamination and severely modify the properties of the metal. To address this issue, non-oxidizing reactants such as $\mathrm{NH}_{3}$ have been used in PE-ALD of transition metals such as Ta, Ti, $\mathrm{Ru}$ and Co. ${ }^{22-25}$ For the plasma source, a mixture of $\mathrm{N}_{2}$ and $\mathrm{H}_{2}$ is used and the properties of the deposited metal thin film largely depend on the $\mathrm{N}_{2} / \mathrm{H}_{2}$ gas flow ratio. ${ }^{23,26}$ It has been observed that a $\mathrm{H}_{2}$ plasma alone or separate $\mathrm{N}_{2}$ and $\mathrm{H}_{2}$ plasmas result in high resistivity and low purity Co thin films. ${ }^{27}$ Previous studies argue that the presence of $\mathrm{NH}_{\mathrm{x}}$ species is needed to deposit low resistivity and high purity Co thin film. ${ }^{27}$ These $\mathrm{NH}_{\mathrm{x}}$ species are proposed to promote the chemisorption of the metal precursor and the removal of the $\mathrm{Cp}$ ligand, analogous to the role of hydroxyl groups in metal oxide ALD $20-21,28-29$. But they are not incorporated in the film, because the $\mathrm{N}$ may desorb in the form of either $\mathrm{NH}_{3}$ or $\mathrm{N}_{2}$.

The incorporation of nitrogen into a PE-ALD deposited Co film is temperature-dependent. The formation of $\mathrm{CoN}_{\mathrm{x}}$ was reported during the deposition of Co thin films using $\mathrm{CoCp}_{2}$ and $\mathrm{NH}_{3}$ plasma at temperatures below $300^{\circ} \mathrm{C}^{30}$. For deposition temperatures above $350^{\circ} \mathrm{C}$, decomposition of $\mathrm{CoN}_{\mathrm{x}}$ was effectively complete, resulting in pure Co thin films. ${ }^{30}$ The detailed mechanism of plasma assisted metal deposition has not yet been established and requires deeper investigations. A plausible proposal is that highly reactive radicals from the hydrogen/nitrogen-plasma source must be present for successful PE-ALD of metals. 
A complete PE-ALD process using N-plasma $\left(\mathrm{NH}_{3} \text { or mixture of } \mathrm{N}_{2} \text { and } \mathrm{H}_{2}\right)^{27}$ can be thought to follow the following process: Firstly, it is vital to note that at the post-plasma stage, the metal surface is actually an $\mathrm{NH}_{\mathrm{x}}$-terminated metal surface, where $\mathrm{x}=1$ or $2 \cdot{ }^{31}$ In the metal half-cycle, the metal precursor $\mathrm{CoCp}_{2}$ reacts with $\mathrm{NH}_{\mathrm{x}}$-terminated metal surface. $\mathrm{Cp}$ ligands are eliminated by hydrogen transfer from the surface to form $\mathrm{CpH}$, which desorbs from surface. ${ }^{32} \mathrm{In}$ the second half-cycle, the plasma generated radicals such as $\mathrm{N}_{\mathrm{x}} \mathrm{H}_{\mathrm{y}}(\mathrm{x}=0,1 ; \mathrm{y}=0,1,2)$ will react with the precursor fragments terminated metal surface, eliminating any remaining metal ligands from the surface, and covering the metal surface in some concentration of $\mathrm{NH}_{\mathrm{x}}$ groups at the end of second half cycle.

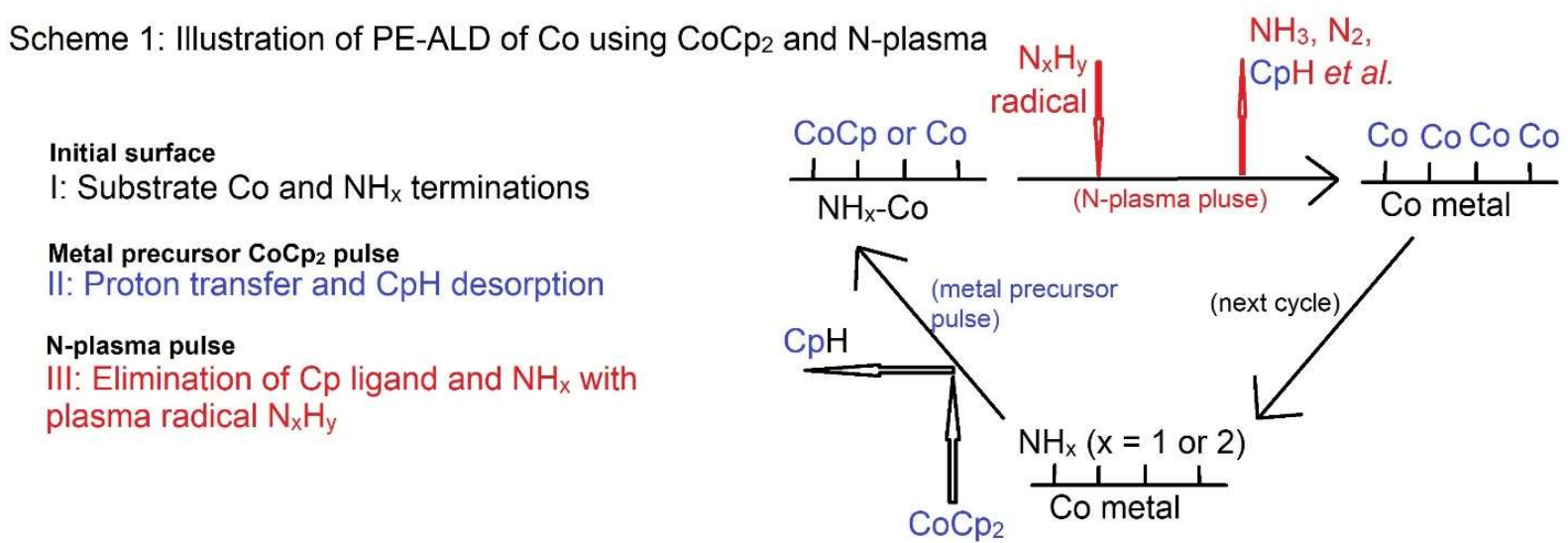

Scheme 1: Illustration of PE-ALD of Co using $\mathrm{CoCp}_{2}$ and $\mathrm{NH}_{3}$ or $\mathrm{N}_{2} / \mathrm{H}_{2}$ plasma.

In our recent published work, the nature and stability of $\mathrm{NH}_{\mathrm{x}}$-terminated $\mathrm{Co}(001)$ and (100) surfaces and the structures after metal precursor $\mathrm{CoCp}_{2}$ pulse were studied. ${ }^{31-32}$ The results show that at typical ALD operating conditions from the literature ${ }^{5}$ (temperature range $550 \mathrm{~K}$ to $650 \mathrm{~K}$ ), the most stable termination of the low energy $(001)$ surface is $0.56 \mathrm{ML}$ coverage of $\mathrm{NH}-$ termination. On the high energy, zig-zag (100) surface, a mixture of 0.67ML NH and 0.67ML $\mathrm{NH}_{2}$ 
is the most stable surface termination. With these $\mathrm{NH}_{\mathrm{x}}$ terminations, on the $\operatorname{Co}(100)$ surface, the metal precursor can undergo two hydrogen transfer steps and the two $\mathrm{Cp}$ ligands are eliminated completely, resulting in Co atom deposition on the surface, whereby Co binds to the $\mathrm{N}$ atom. However, on the $\mathrm{Co}(001)$ surface, only one $\mathrm{Cp}$ ligand is eliminated, resulting in $\mathrm{CoCp}$ fragments on the surface after the metal precursor pulse. The computed surface coverage of final terminations after the metal precursor pulse are $3.03 \mathrm{CoCp} / \mathrm{nm}^{2}$ on $\mathrm{NH}_{\mathrm{x}}$-terminated $\mathrm{Co}(001)$ surface and 3.33 $\mathrm{Co} / \mathrm{nm}^{2}$ on $\mathrm{NH}_{\mathrm{x}}$-terminated $\mathrm{Co}(100)$ surface. ${ }^{32}$

In the present work, we investigate with density functional theory (DFT) the reactions of plasma generated radicals $\mathrm{H}, \mathrm{N}, \mathrm{NH}$, and $\mathrm{NH}_{2}$ with the metal precursor treated $\mathrm{Co}(001)$ and (100) surfaces in detail. We use static DFT relaxations at $0 \mathrm{~K}$ and $a b$ initio MD simulations at $600 \mathrm{~K}$ to explore the chemistry of these radicals and how they remove $\mathrm{Cp}$ ligands, $\mathrm{NH}_{\mathrm{x}}$ species and recover the $\mathrm{NH}_{\mathrm{x}}$ terminations needed to promote the metal precursor step.

We find that $\mathrm{N}$ radicals play an important role in eliminating surface bound $\mathrm{Cp}$ ligands on (001) surface via pyridine formation and desorption and $\mathrm{H}$ radicals can promote the elimination of $\mathrm{NH}_{\mathrm{x}}$ species on the (001) surface via $\mathrm{NH}_{3}$ formation and desorption. These reactions are overall exothermic and surface $\mathrm{Cp}$ ligand and $\mathrm{NH}_{\mathrm{x}}$ species can be removed completely on (001) surface, resulting in deposited Co atoms on (001) surface at a coverage of $3.03 \mathrm{Co} / \mathrm{nm}^{2}$. Further, plasma generated $\mathrm{NH}_{\mathrm{x}}$ species can then cover the (001) surface by reacting with the deposited Co atoms to make new Co-N bonds.

However, on the (100) surface, the surface $\mathrm{NH}_{2}$ species cannot be fully removed via $\mathrm{NH}_{3}$ formation and desorption due to an overall endothermic reaction pathway. H radicals contribute to transform bare $\mathrm{N}$ species in the (100) trench sites to $\mathrm{NH}$. This current paper shows that these $\mathrm{N}$ species are potential sources of $\mathrm{N}$ impurities in Co thin film deposition with PE-ALD. 
These findings confirm that the plasma radicals play a crucial role in adsorbing metal precursor $\mathrm{CoCp} 2$ with the formation of $\mathrm{NH}_{\mathrm{x}}$-terminations on metal surfaces, and the elimination of any remaining $\mathrm{Cp}$ ligands that cannot be completely removed during the metal precursor pulse. For Cp-based metal precursors, $\mathrm{NH}_{\mathrm{x}}$ species are required to deposit Co thin film with high purity and low resistivity, which explains why $\mathrm{NH}_{3}$ plasma or a mixture of $\mathrm{N}_{2}$ and $\mathrm{H}_{2}$ plasma are the most favourable sources for Co deposition, rather than $\mathrm{H}_{2}$ plasma or $\mathrm{N}_{2}$ plasma alone.

\section{Methods and Computational Details}

All the calculations are performed on the basis of periodic spin-polarized density functional theory (DFT) within a plane wave basis set and projector augmented wave (PAW) formalism ${ }^{33}$, as implemented in the Vienna ab initio simulation package (VASP 5.3) code ${ }^{34}$. The generalized gradient approximation (GGA) with the parameterization of Perdew-Burke-Ernzerhof (PBE) is used for the exchange-correlation functional. ${ }^{35-36}$ We use 9 valence electrons for Co, 5 for $\mathrm{N}, 4$ for $\mathrm{C}$, and 1 for $\mathrm{H}$. The plane wave energy cut-off is $400 \mathrm{eV}$. The convergence of energy and forces are set at $1 \times 10^{-4} \mathrm{eV}$ and $0.01 \mathrm{eV} / \AA$, respectively. The bulk Co crystal structure is optimized by simultaneously relaxing the ionic positions, cell volume and cell shape at a higher plane wave energy cut-off of $550 \mathrm{eV}$ and using a Monkhorst-Pack grid k-point mesh ${ }^{37}$ of $12 \times 12 \times 6$. The resulting lattice constants are $\mathrm{a}=\mathrm{b}=2.49 \AA$, and $\mathrm{c}=4.03 \AA$, which are in good agreement with experiment.

The deposited Co films by PE-ALD are polycrystalline and have random surface orientations after low temperature deposition. Based on our previous study ${ }^{31}$ on the stability of $\mathrm{NH} / \mathrm{NH}_{2}$ terminations, we have chosen the most stable (001) surface and a less stable but high reactivity 
surface, namely (100), to investigate the precursor reaction mechanism. A (4×4) supercell is used to model the (001) surface with a surface lattice of $\mathrm{a}=\mathrm{b}=9.96 \AA$ ( $\mathrm{a}(3 \times 3)$ supercell, with a surface lattice of $\mathrm{a}=7.47 \AA, \mathrm{b}=12.10 \AA$ ( surface area $\left.=0.90 \mathrm{~nm}^{2}\right)$, is used to model the (100) surface. For the $\operatorname{Co}(001)$ surface, a five-layer slab is used, with the bottom three layers fixed during the calculation; while for the $\operatorname{Co}(100)$ surface, due to its zigzag structure, a four-bilayer (eight-atomic-layer) slab is built with the bottom two bilayers (bottom four layers) fixed during the calculations. From our previous studies, fixing these-layers is sufficient to model these Co surfaces. ${ }^{31}$ A k-point mesh ${ }^{37}$ of $2 \times 2 \times 1$ is used in $(4 \times 4)$ supercell and for the $(3 \times 3)$ supercell a $3 \times 2 \times 1$ mesh is used. The van der Waals correction was applied with the PBE-D3 method to ensure an accurate description of the dispersion interactions in the computed adsorption energies. ${ }^{38}$ Charge transfer is analysed with the Bader charge analysis procedure. ${ }^{39-40}$ This was computed from the difference between the Bader charge and the number of valence electrons.

From our previous study, after the metal precursor $\left(\mathrm{CoCp}_{2}\right)$ pulse, the surface terminations are CoCp fragments on $\mathrm{NH}_{\mathrm{x}}$-terminated $\mathrm{Co}(001)$ surface at a coverage of $3.03 \mathrm{CoCp} / \mathrm{nm}^{2}$ and deposited Co atoms on $\mathrm{NH}_{\mathrm{x}}$-terminated $\mathrm{Co}(100)$ surface at a coverage of $3.33 \mathrm{Co} / \mathrm{nm}^{2}$. These configurations after the metal precursor pulse are shown in Figure 1. On the $\operatorname{Co}(100)$ surface, mixed $\mathrm{NH}_{\mathrm{x}}$ terminations with $\mathrm{NH}$ occupying trench sites and $\mathrm{NH}_{2}$ occupying surface sites are determined. ${ }^{31}$ Trench NH species contribute to eliminate $\mathrm{Cp}$ ligands during the metal precursor pulse, resulting in bare $\mathrm{N}$ atoms on trench sites (Figure 1(b)).

During the plasma step, the plasma generated radicals $\mathrm{H}, \mathrm{N}, \mathrm{NH}$, and $\mathrm{NH}_{2}$ can remove any surface bound $\mathrm{Cp}$ ligands and surface $\mathrm{NH}_{\mathrm{x}}$ species. At the post-plasma stage, the metal surfaces are supposed to be covered with $\mathrm{NH}_{\mathrm{x}}$-terminations, which is then ready for the next deposition cycle. 
(a)
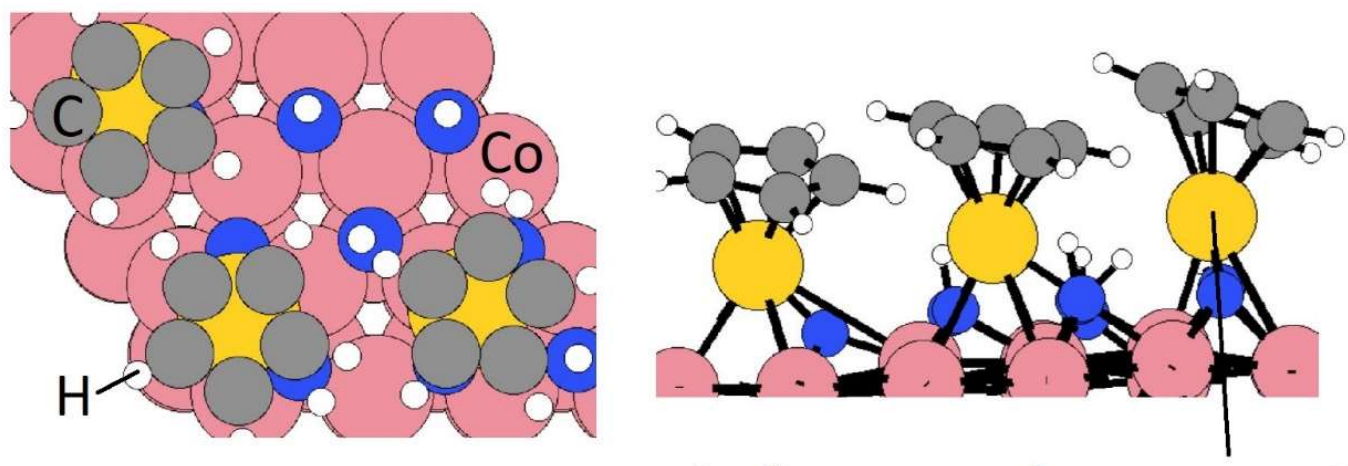

(b)

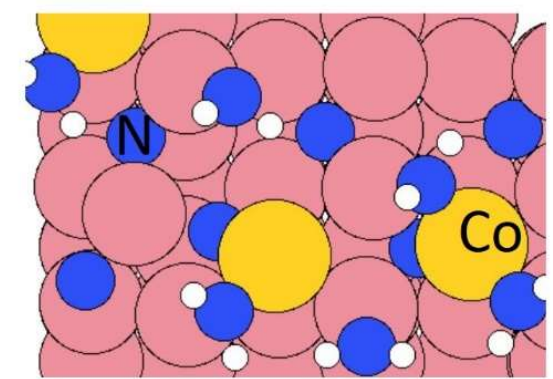

top view

\section{Co from metal precursor $\mathrm{CoCp}_{2}$}



side view

Figure 1. The configurations of final structures on Co (a) (001) and (b) (100) surfaces after metal precursor pulse. Carbon, nitrogen, and hydrogen atoms are presented by grey, blue, and white colour. Substrate Co and $\mathrm{Co}$ from $\mathrm{CoCp}_{2}$ are represented by orange and yellow spheres, respectively.

\section{Results and Discussions}

\subsection{Reactions of one plasma radical with one CoCp fragment on $\mathrm{NH}_{x}$-terminated Co(001) surface}

As a starting point, to assess the chemistry of the possible radicals from the plasma, we have performed static DFT relaxations of a single plasma radical, that being $\mathrm{H}, \mathrm{N}, \mathrm{NH}$, or $\mathrm{NH}_{2}$, which reacts with the Co (001) surface terminated with one CoCp fragment. ${ }^{32}$ These results are summarized in Table S1.

The reaction energies are calculated by

$$
\Delta E=E_{\text {total }}-E_{\text {sub }}-E_{\text {plasma }}
$$


where $E_{\text {total }}$ is the energy of the CoCp- $\mathrm{NH}_{\mathrm{x}}$-terminated Co surface after introducing the plasma radicals. $E_{\text {sub }}$ represents the energy of the $\mathrm{CoCp}-\mathrm{NH}_{\mathrm{x}}$-terminated Co surface. $E_{\text {plasma }}$ is the energy of the plasma generated radicals $\mathrm{H}, \mathrm{N}, \mathrm{NH}$, and $\mathrm{NH}_{2}$. In this study, $\mathrm{H}$ and $\mathrm{N}$ radicals are referenced to half of $\mathrm{H}_{2}$ and $\mathrm{N}_{2}$ while $\mathrm{NH}$ or $\mathrm{NH}_{2}$ radicals are referenced to $1 / 2\left(\mathrm{~N}_{2}+\mathrm{H}_{2}\right)$ or $\left(1 / 2 \mathrm{~N}_{2}\right.$ $+\mathrm{H}_{2}$ ), respectively, which is consistent with our previous thermodynamic study of $\mathrm{NH}_{\mathrm{x}^{-}}$ terminations. $^{31}$

To investigate the formation of $\mathrm{CpH}$ from a single bound $\mathrm{CoCp}$ on the $\mathrm{Co}(001)$ surface, one hydrogen radical is placed near $\mathrm{Cp}$, with an initial C-H distance of $1.90 \AA$. The initial structure and the relaxed stable structure are shown in Figure S1. After relaxing, $\mathrm{CpH}$ is formed spontaneously, with a computed positive reaction energy of $1.93 \mathrm{eV}$ using equation (1) and $\mathrm{C}-\mathrm{H}$ bond distance of 1.1A. The computed energy cost of removing the $\mathrm{CpH}$, resulting one Co atom deposited on the (001) surface, is $2.77 \mathrm{eV}$. After this, the Co-N distance on the surface is $1.73 \AA$, which is slightly shortened compared to surface-terminated $\mathrm{CoCp}$ with $\mathrm{Co}-\mathrm{N}$ distance at $1.74 \AA$. The removal of $\mathrm{Cp}$ ligand for one $\mathrm{CoCp}$ fragment on $\mathrm{Co}(001)$ surface via $\mathrm{CpH}$ formation and desorption is overall endothermic with an energy cost of $4.70 \mathrm{eV}$, so this pathway is not a favourable pathway for eliminating $\mathrm{Cp}$ ligand at plasma cycle and we therefore do not expect release of $\mathrm{CpH}$ during the plasma half reaction.

An alternative chemistry is that $\mathrm{N}$ or $\mathrm{NH}$ radicals can react with a $\mathrm{Cp}$ ligand and insert into a $\mathrm{C}=\mathrm{C}$ bond to form pyridine $\left(\mathrm{C}_{5} \mathrm{H}_{4} \mathrm{~N}\right)$ or the pyridinium cation $\left(\mathrm{C}_{5} \mathrm{H}_{5} \mathrm{NH}\right)$. The configurations of relaxed structures after inserting single $\mathrm{N}$ or $\mathrm{NH}$ radical into a $\mathrm{C}=\mathrm{C}$ bond of the $\mathrm{Cp}$ ligand are shown in Figure S2; the computed reaction energies in these cases are $-0.07 \mathrm{eV}$ for pyridine and $0.23 \mathrm{eV}$ for pyridinium. The computed energy cost of removing pyridine or pyridinium, resulting one Co atom deposited on the surface, are $2.39 \mathrm{eV}$ and $2.77 \mathrm{eV}$, respectively. Pyridine has overall less positive 
reaction energies and is less endothermic than pyridinium and $\mathrm{CpH}$, so we could expect pyridine as the primary elimination product during the plasma cycle.

Turning now to the surface $\mathrm{NH}_{\mathrm{x}}$ species, these can be removed via successive hydrogenation $\mathrm{NH}$ $\rightarrow \mathrm{NH}_{2} \rightarrow \mathrm{NH}_{3}$ with $\mathrm{H}$ radicals. We consider firstly that the $\mathrm{Cp}$ ligand is present throughout the process of elimination of surface $\mathrm{NH}$ species on the $\mathrm{Co}(001)$ surface terminated with a single $\mathrm{CoCp}$ fragment. The reaction energies along the elimination of $\mathrm{NH}_{\mathrm{x}}$ species are calculated by

$$
\Delta E=E_{\text {total }}-E_{\text {sub }}-n * E_{H}+m * E_{N H 3}
$$

where $E_{\text {total }}$ and $E_{\text {sub }}$ are the energies of plasma $\mathrm{H}$ radical treated $\mathrm{CoCp}-\mathrm{NH}_{\mathrm{x}}$-terminated Co (001) surface and the single CoCp- $\mathrm{NH}_{\mathrm{x}}$-terminated $\mathrm{Co}(001)$ surface, respectively. $E_{H}$ is the energy of plasma generated $\mathrm{H}$ radical, which is referenced to half of $\mathrm{H}_{2} . E_{N H 3}$ is the energy of $\mathrm{NH}_{3}$ that desorbs from metal surface.

One $\mathrm{H}$ radical is placed near one surface $\mathrm{NH}$ species with an initial N-H distance of $1.5 \AA$, where the $\mathrm{Cp}$ ligand is present on the surface. The configurations of the initial and relaxed stable structures are shown in Figure $\mathrm{S} 3$. The intermediate $\mathrm{NH}_{2}$ is formed spontaneously, with a positive reaction energy of $1.21 \mathrm{eV}$ and $\mathrm{N}-\mathrm{H}$ bond distance of $1.0 \AA$. We then add an additional $\mathrm{H}$ radical near this $\mathrm{NH}_{2}$ species. After relaxing the structure, $\mathrm{NH}_{3}$ is formed spontaneously, with an energy gain of $-0.51 \mathrm{eV}$ and the computed energy cost of the $\mathrm{NH}_{3}$ desorption is $0.80 \mathrm{eV}$. The removal of first $\mathrm{NH}$ species on $\mathrm{Co}(001)$ surface with the presence of one $\mathrm{CoCp}$ fragment via $\mathrm{NH}_{3}$ formation and desorption is overall endothermic with an energy cost of $1.50 \mathrm{eV}$.

Figure 2 shows the reaction pathway for elimination of up to $4 \mathrm{NH}$ surface species via $\mathrm{NH} \rightarrow \mathrm{NH}_{2}$ $\rightarrow \mathrm{NH}_{3}$ for the case in which the $\mathrm{Cp}$ ligand is present throughout. This pathway is overall endothermic. The computed reaction energies for intermediate $\mathrm{NH}_{2}$ formation, by-product $\mathrm{NH}_{3}$ 
formation and desorption are positive in the range of $0.06 \mathrm{eV}$ to $1.07 \mathrm{eV}$, except for the $3^{\text {rd }} \mathrm{NH}_{3}$ formation, which has an exothermic energy at $-0.19 \mathrm{eV}$. The configurations of structures along the pathway are shown in Figure S4.

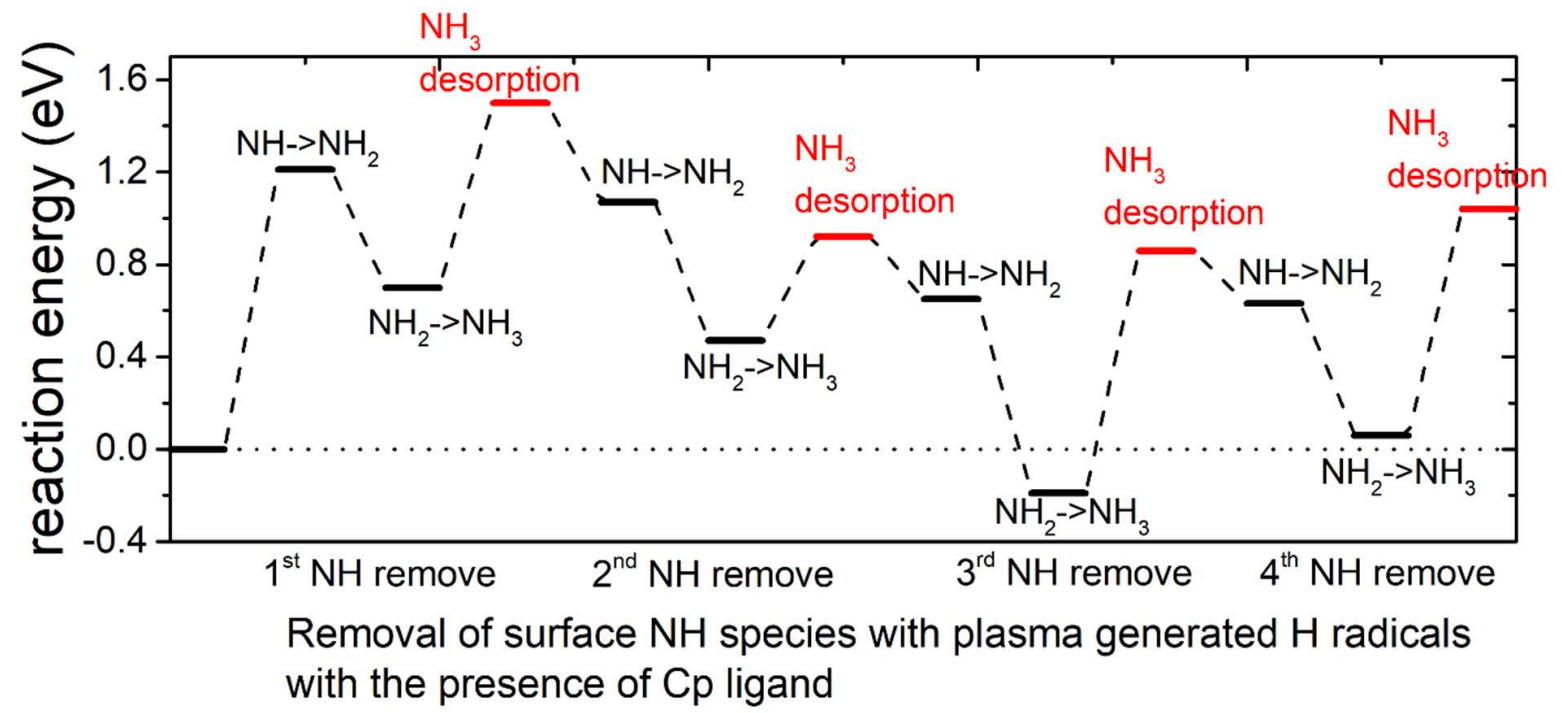

Figure 2. The plotted reaction pathway for removal of surface $\mathrm{NH}$ species with plasma generated $\mathrm{H}$ radicals with the presence of $\mathrm{Cp}$ ring on one $\mathrm{CoCp}$-terminated $\mathrm{Co}(001)$ surface. The energy of $\mathrm{Co}(001)$ surface with $\mathrm{NH}_{\mathrm{x}}$-termination and one CoCp fragment is set to be the reference energy at $0 \mathrm{eV}$.

The alternative situation is that $\mathrm{Cp}$ is first eliminated as pyridine and in Figure 3, we show the reaction pathway for this case. Now the reactions of intermediate $\mathrm{NH}_{2}$ formation and by-product $\mathrm{NH}_{3}$ formation and desorption are overall exothermic, except for the initial removal of $\mathrm{Cp}$ ligand and $\mathrm{NH}_{3}$ desorption. The computed energy cost of $\mathrm{NH}_{3}$ desorption are in the range of $-1.41 \mathrm{eV}$ to $1.86 \mathrm{eV}$. The positive energy cost is still likely to be overcome by the energy available from plasmagenerated excited $\mathrm{H}$ radicals at plasma operating condition. The configurations of structures along the pathway are shown in Figure S5. 




Removal of surface $\mathrm{NH}$ species with plasma generated $\mathrm{H}$ radicals with initial $\mathrm{Cp}$ ligand removal via pyridine formation and desorption

Figure 3. The plotted reaction pathway for removal of surface $\mathrm{NH}$ species with plasma generated $\mathrm{H}$ radicals with initial $\mathrm{Cp}$ ligand removed on one CoCp-terminated $\mathrm{Co}(001)$ surface. The energy of $\mathrm{Co}(001)$ surface with $\mathrm{NH}_{\mathrm{x}}$-termination and one CoCp fragment is set to be the reference energy at $0 \mathrm{eV}$. The steps of $\mathrm{H}$ radical addition are indicated by the black markers and the steps of $\mathrm{NH}_{3}$ desorption are indicated by the red markers. $\mathrm{CpH}$ is first eliminated as pyridine.

The plotted reaction energies for the case that $\mathrm{Cp}$ is first eliminated as $\mathrm{CpH}$ is shown in Figure S6. We see that the computed reaction energies of $\mathrm{CpH}$ and $\mathrm{NH}_{3}$ formation and desorption are all positive and the reactions are endothermic, compared to overall exothermic reactions via $\mathrm{Cp}$ eliminated as pyridine. We would expect that pyridine is the primary product from eliminating $\mathrm{Cp}$ ligand during plasma cycle.

Compared to overall endothermic reactions with the presence of $\mathrm{Cp}$ ligand in the elimination process, the reactions of surface $\mathrm{NH}$ with $\mathrm{H}$ radical when the Cp ligand is removed in the first step are overall exothermic. We applied Bader charge analysis to the structures formed for both the $\mathrm{NH}_{2}$ intermediate and the ammonia by-product for the cases in which the Cp ligand is present and the $\mathrm{Cp}$ ligand was removed prior to formation of surface $\mathrm{NH}_{\mathrm{x}}$ species. The results are summarized in Table 1. 
Table 1. The computed charge transfer with Bader charge analysis, $\mathrm{q}$ (Bader) - $\mathrm{q}($ valence), for the elimination of surface $\mathrm{NH}$ species with the presence of $\mathrm{Cp}$ ligand and $\mathrm{Cp}$ ligand removed prior to surface $\mathrm{NH}_{\mathrm{x}}$ species.

\begin{tabular}{lllllllll}
\hline & \multicolumn{2}{l}{$1^{\text {st }} \mathrm{NH}$ removal } & \multicolumn{2}{c}{$2^{\text {nd }} \mathrm{NH}$ removal } & \multicolumn{2}{c}{$3^{\text {rd }} \mathrm{NH}$ removal } & \multicolumn{2}{c}{$4^{\text {th }} \mathrm{NH}$ removal } \\
\hline & $\mathrm{NH}_{2}$ & $\mathrm{NH}_{3}$ & $\mathrm{NH}_{2}$ & $\mathrm{NH}_{3}$ & $\mathrm{NH}_{2}$ & $\mathrm{NH}_{3}$ & $\mathrm{NH}_{2}$ & $\mathrm{NH}_{3}$ \\
\hline Cp ligand present & $0.43 \mathrm{e}^{-}$ & $-0.08 \mathrm{e}^{-}$ & $0.36 \mathrm{e}^{-}$ & $-0.07 \mathrm{e}^{-}$ & $0.35 \mathrm{e}^{-}$ & $-0.07 \mathrm{e}^{-}$ & $0.38 \mathrm{e}^{-}$ & $-0.11 \mathrm{e}^{-}$ \\
\hline Cp ligand removed & $0.42 \mathrm{e}^{-}$ & $-0.08 \mathrm{e}^{-}$ & $0.37 \mathrm{e}^{-}$ & $-0.05 \mathrm{e}^{-}$ & $0.32 \mathrm{e}^{-}$ & $-0.05 \mathrm{e}^{-}$ & $0.35 \mathrm{e}^{-}$ & $-0.06 \mathrm{e}^{-}$ \\
\hline
\end{tabular}

For both cases, the transferred charge to intermediate $\mathrm{NH}_{2}$ shows no differences and is in the range of $0.35 \mathrm{e}^{-}$to $0.43 \mathrm{e}^{-}$for each $\mathrm{NH}_{2}$ formation step. For the ammonia formation step, if the $\mathrm{Cp}$ ligand is present throughout the elimination of surface $\mathrm{NH}$ species, there is an increasing trend of charge transfer from $\mathrm{NH}_{3}$ to the substrate, which suggests an increasing interaction between surface Co atoms and $\mathrm{NH}_{3}$. When the $\mathrm{Cp}$ ligand is removed prior to the $\mathrm{NH}$ species, the transferred charge from $\mathrm{NH}_{3}$ to substrate shows a decreasing trend, which suggests a decreasing interaction between surface Co atoms and $\mathrm{NH}_{3}$. We can infer that the computed positive reaction energies for the presence of $\mathrm{Cp}$ ligand in the elimination process is due to the stronger interaction (more charge transfer) between $\mathrm{NH}_{3}$ and substrate $\mathrm{Co}$ atoms. Thus, the removal of the $\mathrm{Cp}$ ligand prior to surface $\mathrm{NH}_{\mathrm{x}}$ species is the preferred reaction mechanism and most of the surface $\mathrm{NH}_{\mathrm{x}}$ species will be removed with plasma-generated $\mathrm{H}$ radicals for lower CoCp coverage case.

\subsection{Reaction of plasma radicals at Co (001) with CoCp coverage of $3.03 \mathrm{CoCp} / \mathrm{nm}^{2}$}

Building on the analysis of the chemistry of the plasma radicals with the low coverage of CoCp, we next examine the interaction of plasma radicals $\mathrm{H}, \mathrm{N}$, and $\mathrm{NH}$ with $\mathrm{CoCp}$ on the $\mathrm{NH}_{\mathrm{x}^{-}}$ 
terminated $\mathrm{Co}(001)$ surface at the highest, stable coverage of $3.03 \mathrm{CoCp} / \mathrm{nm}^{2}{ }^{32}$ In the first calculations of section 3.1, the coverages of plasma radicals are one plasma radical per CoCp fragment, so at the highest stable coverage of CoCp fragments, we consider $3 \mathrm{H}, 3 \mathrm{~N}$, and $3 \mathrm{NH}$, respectively. These results are summarized in Table 2 .

The reaction energies per plasma radical are calculated by

$$
\Delta E=\left(E_{\text {total }}-E_{\text {sub }}-E_{n * \text { plasma }}\right) / n
$$

where $E_{\text {total }}$ and $E_{\text {sub }}$ are the energies of plasma radicals treated $(\mathrm{CoCp})_{3} \mathrm{NH}_{\mathrm{x}}$-terminated Co (001) surface the $(\mathrm{CoCp})_{3} \mathrm{NH}_{\mathrm{x}}$-terminated Co (001) surface, respectively. $E_{\text {plasma }}$ is the total energies of plasma generated radicals, i.e. $3 \mathrm{H}, 3 \mathrm{~N}, 3 \mathrm{NH}$, and $3 \mathrm{NH}_{2}$ as defined above. The reference energies of these plasma radicals are indicated in section 3.1.

Table 2. Summary of reactions of surface species, i.e. $\mathrm{Cp}$ ligand and $\mathrm{NH}_{\mathrm{x}}$ species, and plasma radicals $\mathrm{H}$, $\mathrm{N}$, and $\mathrm{NH}$ on $\mathrm{CoCp}$ fragments on $\mathrm{NH}_{\mathrm{x}}$-terminated $\mathrm{Co}(001)$ surface at the coverage of $3.03 \mathrm{CoCp} / \mathrm{nm}^{2}$. The coverages of plasma radicals are one plasma radical per CoCp fragment, which are $3 \mathrm{H}, 3 \mathrm{~N}$, and $3 \mathrm{NH}$. The by-products are formed spontaneously after structure relaxing.

\begin{tabular}{cccc}
\hline Surface species & Plasma radicals & by-product & $\begin{array}{c}\text { desorption energy per } \\
\text { by-product/eV }\end{array}$ \\
\hline $3 \mathrm{Cp}$ & $3 \mathrm{H}$ & $3 \mathrm{CpH}\left(\mathrm{C}_{5} \mathrm{H}_{6}\right)$ & 1.29 \\
& $3 \mathrm{~N}$ & 3 Pyridine $\left(\mathrm{C}_{5} \mathrm{H}_{5} \mathrm{~N}\right)$ & 1.17 \\
& $3 \mathrm{NH}$ & 3 Pyridinium $\left(\mathrm{C}_{5} \mathrm{H}_{5} \mathrm{NH}\right)$ & 2.25 \\
\hline $3 \mathrm{NH}$ & $3 \mathrm{H}$ & $3 \mathrm{NH}_{2}$ & - \\
\hline $3 \mathrm{NH}_{2}$ & $3 \mathrm{H}$ & $3 \mathrm{NH}_{3}$ & 1.01 \\
\hline
\end{tabular}

We first investigated the elimination of the $\mathrm{Cp}$ ligand via $\mathrm{CpH}$ formation and desorption. One hydrogen radical is placed near each $\mathrm{Cp}$ ring with an initial $\mathrm{C}-\mathrm{H}$ distance of $1.9 \AA$. The initial structure and relaxed stable structure are shown in Figure 4. After relaxing, $3 \mathrm{CpH}$ are formed 
spontaneously, with an energy change of $0.03 \mathrm{eV} / \mathrm{Cp}$ and $\mathrm{C}-\mathrm{H}$ bond distance of $1.1 \AA$. The computed energy cost per $\mathrm{CpH}$ for the desorption process, which results in three Co atoms deposited on the Co (001) surface, is $1.29 \mathrm{eV} / \mathrm{Cp}$. The removal of $\mathrm{Cp}$ ligand for maximum three $\mathrm{CoCp}$ fragments on $\mathrm{Co}(001)$ surface via $\mathrm{CpH}$ formation and desorption is overall endothermic with an energy cost of $1.32 \mathrm{eV} / \mathrm{Cp}$. This is significantly reduced compared with the energy cost of $\mathrm{CpH}$ formation and desorption on one CoCp fragment terminated (001) surface and indicates a cooperative role of the surface bound CoCp species in promoting ligand elimination at this higher coverage. This cooperative effect means that once sufficient numbers of precursor fragments/molecules are present on the metal surface, it can show enhanced activity for ligand exchange and desorption with lower energy cost, which is analogous to cooperative mechanism on proton transfer and ligand desorption for $\mathrm{ALD}$ of metal oxide such as $\mathrm{Al}_{2} \mathrm{O}_{3}$ and $\mathrm{HfO}_{2}{ }^{41}$

For the formation of pyridine or pyridinium cation, one $\mathrm{N}$ or $\mathrm{NH}$ radical is allowed to insert into a $\mathrm{C}=\mathrm{C}$ bond in each $\mathrm{Cp}$ ligand. The configurations of relaxed structures are shown in Figure 5. The energy change upon $\mathrm{N}$ or $\mathrm{NH}$ insertion is $-2.23 \mathrm{eV} / \mathrm{Cp}$ and $-2.62 \mathrm{eV} / \mathrm{Cp}$, respectively. The computed energy cost per pyridine or pyridinium for the desorption process, resulting in three Co atoms deposited on the (001) surface, are $1.17 \mathrm{eV} /$ pyridine and $2.25 \mathrm{eV} /$ pyridinium, respectively. This energy cost is reduced compared with that for the (001) surface with lower CoCp coverage. Overall, the $\mathrm{Cp}$ ligand elimination via pyridine or pyridinium formation and desorption are exothermic at the highest stable coverages of $\mathrm{CoCp}$, whereas it is overall endothermic for $\mathrm{Cp}$ ligand elimination via $\mathrm{CpH}$ formation and desorption. Thus, the expected primary product of eliminating $\mathrm{Cp}$ ligand is pyridine, which is the same as the case of lower CoCp coverage. 
(a)

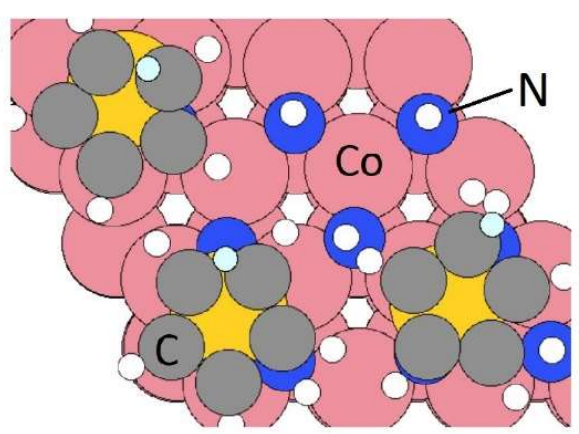

(b)

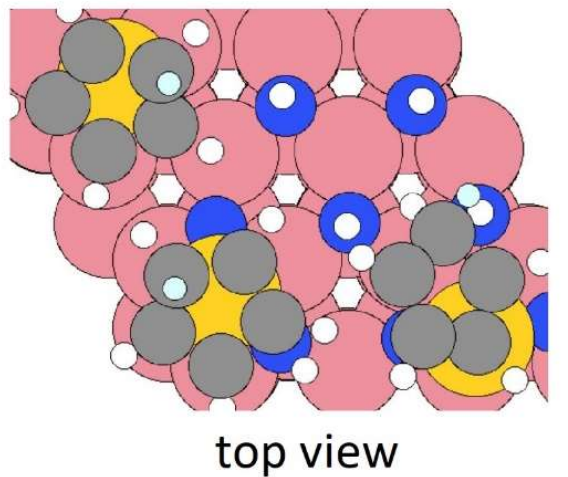

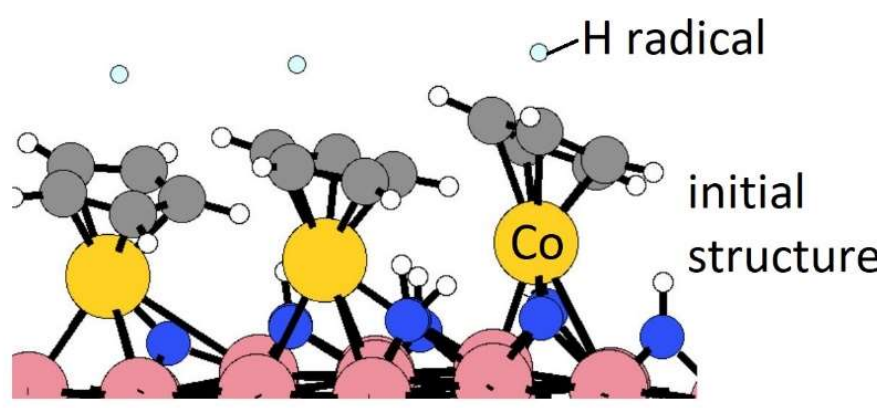



side view

Figure 4. Configurations of top view and side view of (a) initial structure, and (b) relaxed structure for reactions of $\mathrm{H}$ radical and $\mathrm{Cp}$ ligand on $\mathrm{NH}_{\mathrm{x}}$-terminated $\mathrm{Co}(001)$ surface at the coverage of $3.03 \mathrm{CoCp} / \mathrm{nm}^{2}$. Carbon, nitrogen, and hydrogen atoms are presented by grey, blue, and white colour. $\mathrm{H}$ radicals are represented by light blue sphere. Substrate Co and Co from $\mathrm{CoCp}_{2}$ are represented by orange and yellow spheres, respectively.

(a)

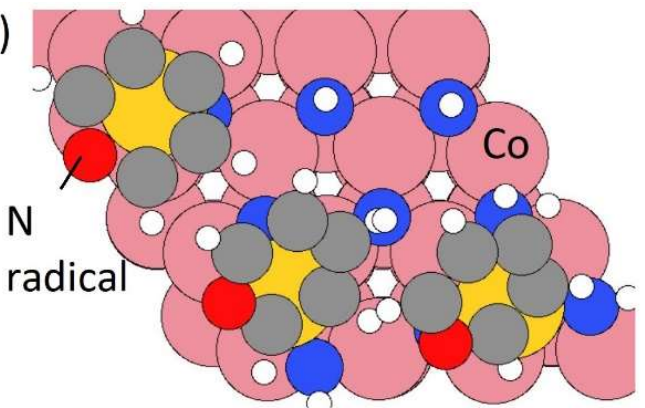

(b)

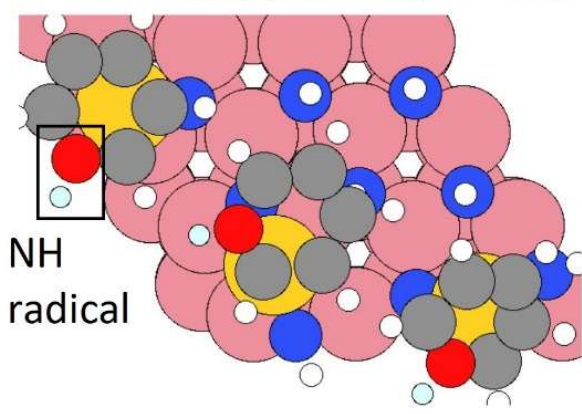

top view
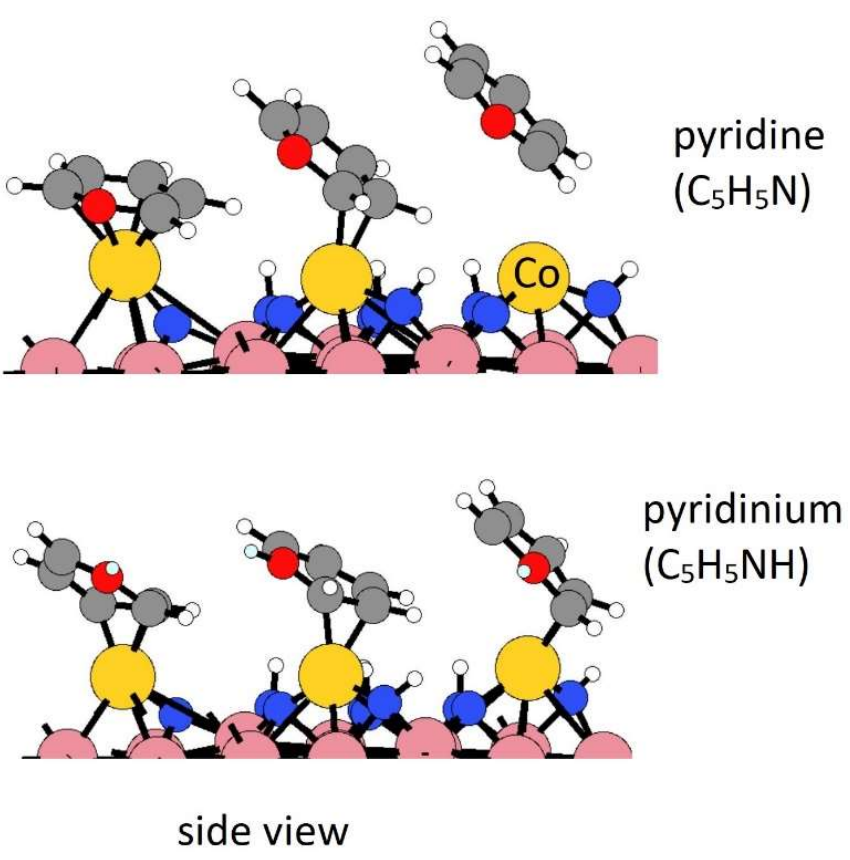
Figure 5. Configurations of top view and side view of (a) $\mathrm{C}_{5} \mathrm{H}_{5} \mathrm{~N}$, (b) $\mathrm{C}_{5} \mathrm{H}_{5} \mathrm{NH}$ for the insertion of plasma radicals $\mathrm{N}$, or $\mathrm{NH}$ into a $\mathrm{C}=\mathrm{C}$ bond of the $\mathrm{Cp}$ ligand on $\mathrm{NH}_{\mathrm{x}}$-terminated $\mathrm{Co}(001)$ surface at the coverage of $3.03 \mathrm{CoCp} / \mathrm{nm}^{2}$. Carbon, nitrogen, and hydrogen atoms are presented by grey, blue, and white colour. Substrate Co and Co from $\mathrm{CoCp}_{2}$ are represented by orange and yellow spheres, respectively. Plasma generated $\mathrm{N}$ and $\mathrm{H}$ radicals are represented by red and light blue spheres, respectively.

To investigate the interaction with the surface $\mathrm{NH}_{\mathrm{x}}$ species, $3 \mathrm{H}$ radicals are placed near three surface NH species with initial H-N distances at $1.5 \AA$ and CoCp fragments are present on the surface. The configurations of initial and relaxed stable structures of intermediate $\mathrm{NH}_{2}$ formation are shown in Figure 6. After the formation of intermediate $\mathrm{NH}_{2}$, with a computed negative reaction energy of $-0.10 \mathrm{eV} / \mathrm{H}$ and $\mathrm{N}-\mathrm{H}$ bond distance of $1.0 \AA, 3$ additional $\mathrm{H}$ radicals are then positioned near these surface $\mathrm{NH}_{2}$ species. After relaxing, $\mathrm{NH}_{3}$ forms spontaneously as shown in Figure 7 , with an energy gain of $-1.05 \mathrm{eV} / \mathrm{H}$. The computed energy cost per $\mathrm{NH}_{3}$ for the desorption process is $1.01 \mathrm{eV} / \mathrm{NH}_{3}$, but this is more than offset by the exothermicity of the $\mathrm{NH}$ and $\mathrm{NH}_{2}$ formation steps.

(a)
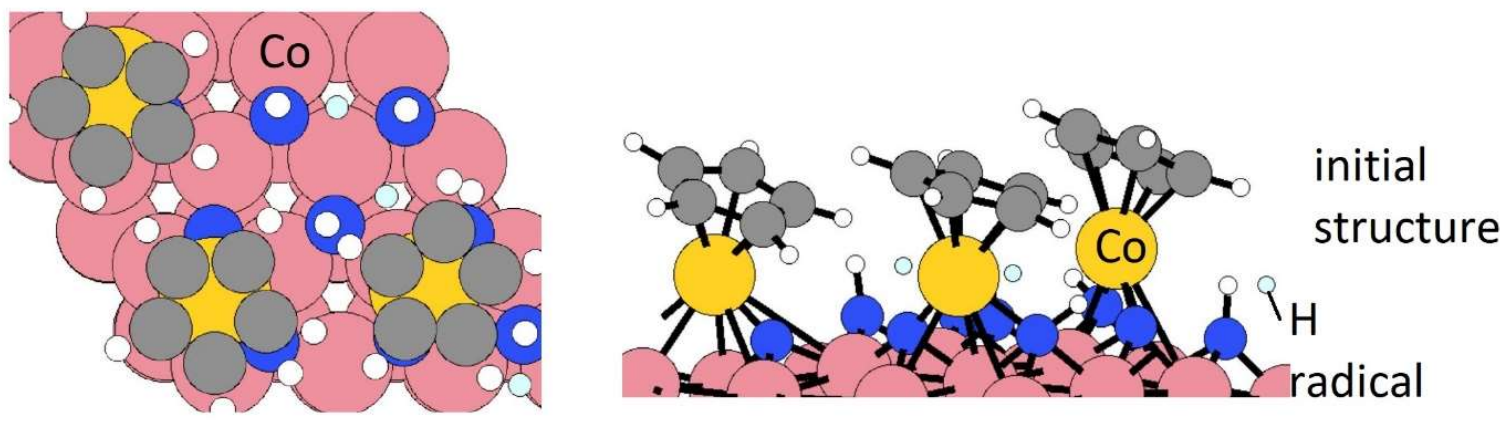

(b)

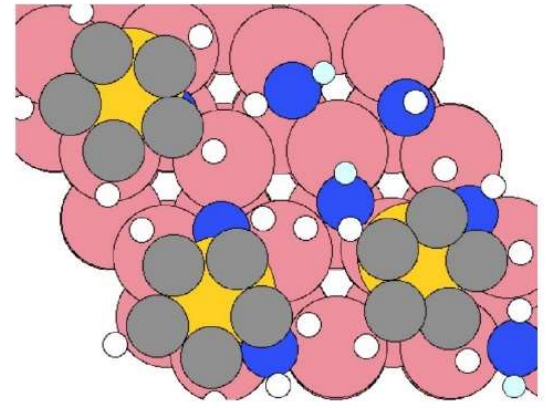

top view

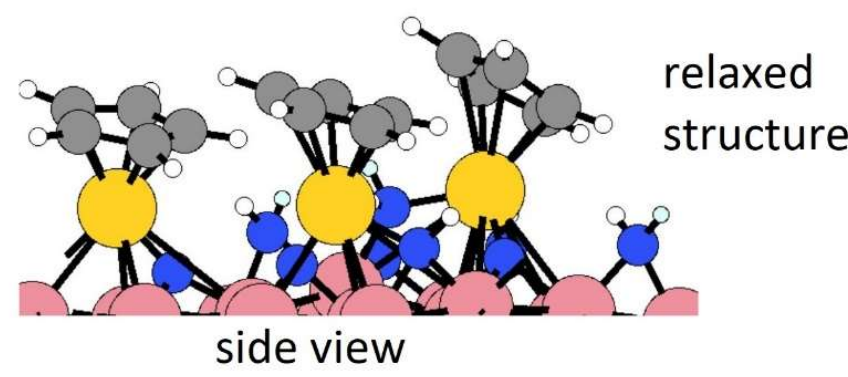


Figure 6. Configurations of top view and side view of (a) initial and (b) relaxed structure for intermediate $\mathrm{NH}_{2}$ formation with $\mathrm{H}$ radical. Carbon, nitrogen, and hydrogen atoms are presented by grey, blue, and white colour. $\mathrm{H}$ radicals are represented by light blue sphere. Substrate Co and Co from $\mathrm{CoCp}_{2}$ are represented by orange and yellow spheres, respectively.

(a)

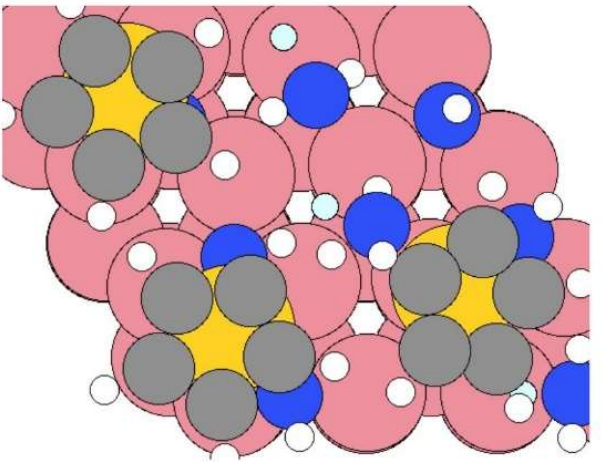

(b)



initial structure

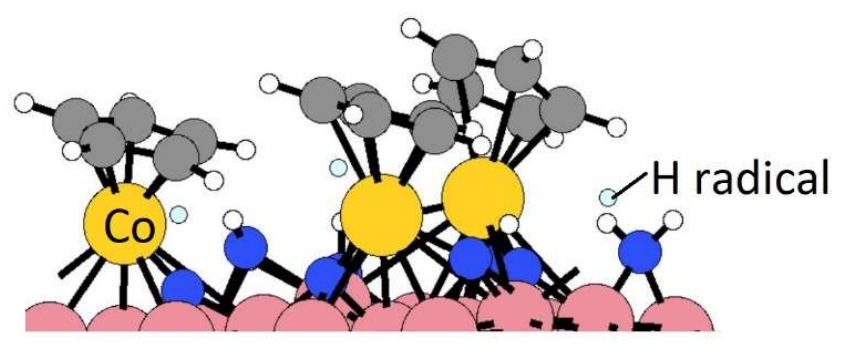

relaxed structure

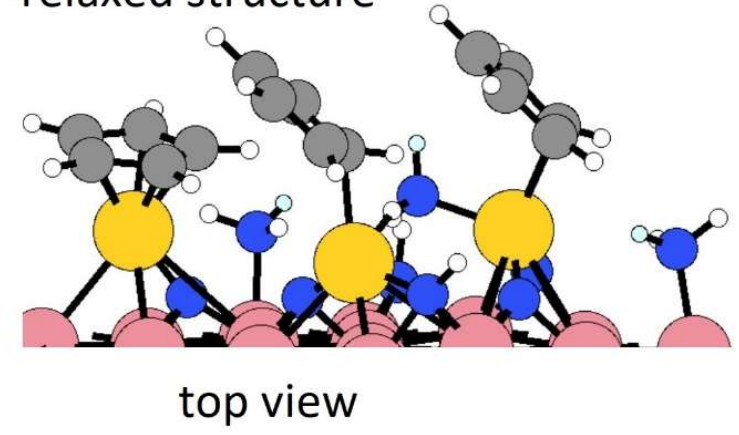

Figure 7. Configurations of top view and side view of (a) initial and (b) relaxed structure for ammonia formation with $\mathrm{H}$ radical and intermediate $\mathrm{NH}_{2}$. Carbon, nitrogen, and hydrogen atoms are presented by grey, blue, and white colour. $\mathrm{H}$ radicals are represented by light blue sphere. Substrate Co and Co from $\mathrm{CoCp} 2$ are represented by orange and yellow spheres, respectively.

We now consider the elimination of $\mathrm{NH}_{\mathrm{x}}$ on $\mathrm{Co}(001)$ surface terminated with $3 \mathrm{CoCp}$ using $\mathrm{H}$ radicals, in which the $\mathrm{Cp}$ ligand was removed in the first step via pyridine formation and desorption. The reaction energies are computed using equation (2) in section 3.1.

The computed reaction energies for initial $\mathrm{Cp}$ ligand removal and subsequent ammonia formation are all negative on $3 \mathrm{CoCp}$-terminated $\mathrm{Co}(001)$ surface. A cooperative effect of the surface-bound CoCp fragments is observed when compared to single CoCp fragment, which makes the removal of Cp ligand exothermic and favourable on the surface with the higher CoCp-coverages. For the 
removal of surface $\mathrm{NH}$ species, the determined preferred pathway is an exothermic $\mathrm{NH} \rightarrow \mathrm{NH}_{2} \rightarrow$ $\mathrm{NH}_{3}$. After the $\mathrm{Cp}$ ligand and $\mathrm{NH}_{\mathrm{x}}$ species are removed completely, three Co atoms are deposited on the $\operatorname{Co}(001)$ surface, with a computed exothermic reaction energy of $-4.85 \mathrm{eV}$. The plotted reaction pathway and configurations of structures along the pathway are shown in Figure 8 and Figure S7, respectively.

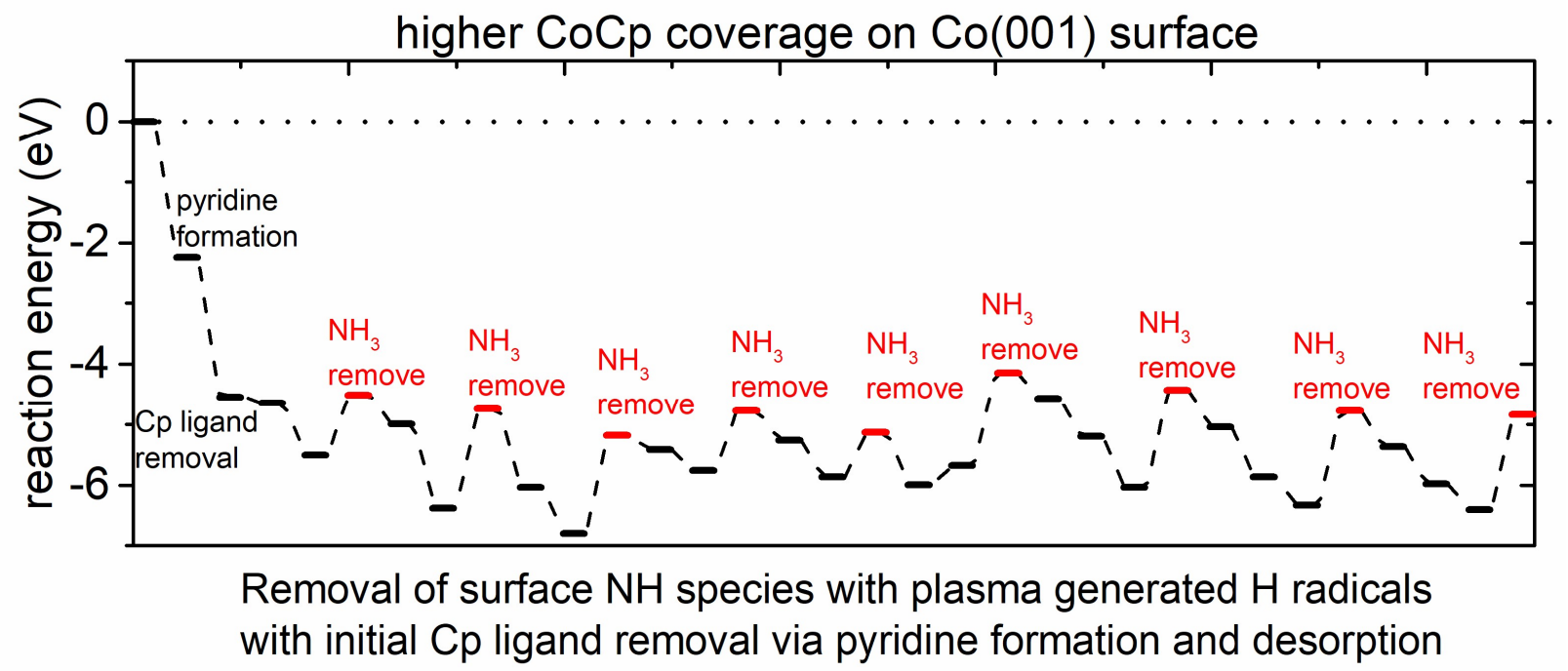

Figure 8. The plotted reaction pathway for removal of surface $\mathrm{NH}$ species with plasma generated $\mathrm{H}$ radicals with initial $\mathrm{Cp}$ ligand removed on $3 \mathrm{CoCp}$-terminated $\mathrm{Co}(001)$ surface. The steps of $\mathrm{H}$ radical addition are indicated by the black markers and the steps of $\mathrm{NH}_{3}$ desorption are indicated by the red markers. The $\mathrm{Cp}$ ligand is first eliminated as pyridine.

The plotted reaction energies for the case that $\mathrm{Cp}$ is first eliminated as $\mathrm{CpH}$ is shown in Figure $\mathrm{S} 8$.

We see that the computed reaction energies of $\mathrm{CpH}$ and $\mathrm{NH}_{3}$ formation and desorption are all positive and the reactions are endothermic, compared to overall exothermic reactions via $\mathrm{Cp}$ eliminated as pyridine. We would expect that pyridine is a primary product from eliminating $\mathrm{Cp}$ ligand during plasma cycle. 
To summarize, these $\mathrm{T}=0 \mathrm{~K}$ results indicate that the $\mathrm{N}$ radical plays an important role in eliminating $\mathrm{Cp}$ ligands present on the surface (if any) via pyridine formation and desorption and $\mathrm{H}$ radicals contribute to the elimination of surface $\mathrm{NH}_{\mathrm{x}}$ species via $\mathrm{NH}_{3}$ formation and desorption.

The elimination process of surface $\mathrm{NH}$ species is exothermic when using $\mathrm{H}$ radicals. $\mathrm{NH}$ species are removed via intermediate $\mathrm{NH}_{2}$ formation, by-product $\mathrm{NH}_{3}$ formation and desorption. Surface $\mathrm{N}$ species, resulting from $\mathrm{H}$ transfer to $\mathrm{Cp}$ ligand on metal precursor pulse, are also removed via $\mathrm{NH}, \mathrm{NH}_{2}$ formation, and release of $\mathrm{NH}_{3}$. The surface $\mathrm{NH}_{\mathrm{x}}$ species are completely eliminated with plasma generated $\mathrm{H}$ radicals, resulting in deposition of $\mathrm{Co}$ atoms on the $\mathrm{Co}(001)$ surface at a coverage of $3.03 \mathrm{Co} / \mathrm{nm}^{2}$.

\subsection{Reactions of plasma generated $\mathrm{H}$ radicals on $\mathrm{NH}_{x}$-terminated Co(100) surface}

After metal precursor $\left(\mathrm{CoCp}_{2}\right)$ pulse, the higher energy Co (100) surface is terminated with Co atoms at a coverage of $3.33 \mathrm{Co} / \mathrm{nm}^{2}$. From our previous study ${ }^{32}$ on the mechanism of metal precursor pulse, the trench $\mathrm{NH}$ species are involved in the $\mathrm{H}$ transfer to eliminate $\mathrm{Cp}$ ligand as $\mathrm{CpH}$. The surface $\mathrm{NH}_{2}$ species have endothermic reaction energies for $\mathrm{CpH}$ elimination. Thus, after the metal precursor pulse in a $(3 \times 3)$ supercell we have three deposited Co atoms with six surface $\mathrm{NH}_{2}$ and six trench $\mathrm{N}$ atoms that have lost $\mathrm{H}$ atoms in the metal precursor step.

During the plasma step, these remaining $\mathrm{NH}_{\mathrm{x}}$ species may be eliminated by the reaction with plasma generated radicals $\mathrm{H}, \mathrm{N}, \mathrm{NH}$, and $\mathrm{NH}_{2}$ via $\mathrm{NH}_{3}, \mathrm{~N}_{2} \mathrm{H}_{2}$, or $\mathrm{N}_{2} \mathrm{H}_{4}$ formation and desorption, analogous to the removal of surface $\mathrm{NH}_{\mathrm{x}}$ species on the $\mathrm{Co}(001)$ surface. We first performed calculations for reactions of eliminating surface $\mathrm{NH}_{2}$ species with $\mathrm{H}$ radicals via $\mathrm{NH}_{3}$ formation and desorption. $\mathrm{H}$ radicals are placed near surface $\mathrm{NH}_{2}$ with an initial $\mathrm{N}-\mathrm{H}$ distance at $1.5 \AA$ and 
examine successive interactions of surface $\mathrm{NH}_{2}$. The plotted energy pathway for ammonia formation and desorption is shown in Figure 9. The reaction energies are calculated using the equation (2) described in section 3.1. The configurations of structures along the reaction pathway is shown in Figure S9. While ammonia is formed spontaneously after relaxing the structure, the computed reaction energies are all positive, indicating endothermic reactions for removal of surface $\mathrm{NH}_{2}$ species with $\mathrm{H}$ radicals. The energy cost of $\mathrm{NH}_{3}$ desorption on $\mathrm{Co}(100)$ surface is around $1.2 \mathrm{eV}$ at each desorption step. After the desorption of the $6^{\text {th }} \mathrm{NH}_{3}$, the overall reaction energy is as high as $5.80 \mathrm{eV}$. This indicates that on $\mathrm{NH}_{\mathrm{x}}$-terminated $\mathrm{Co}(100)$ surface, the surface $\mathrm{NH}_{2}$ species cannot be completely eliminated by $\mathrm{H}$ radicals.

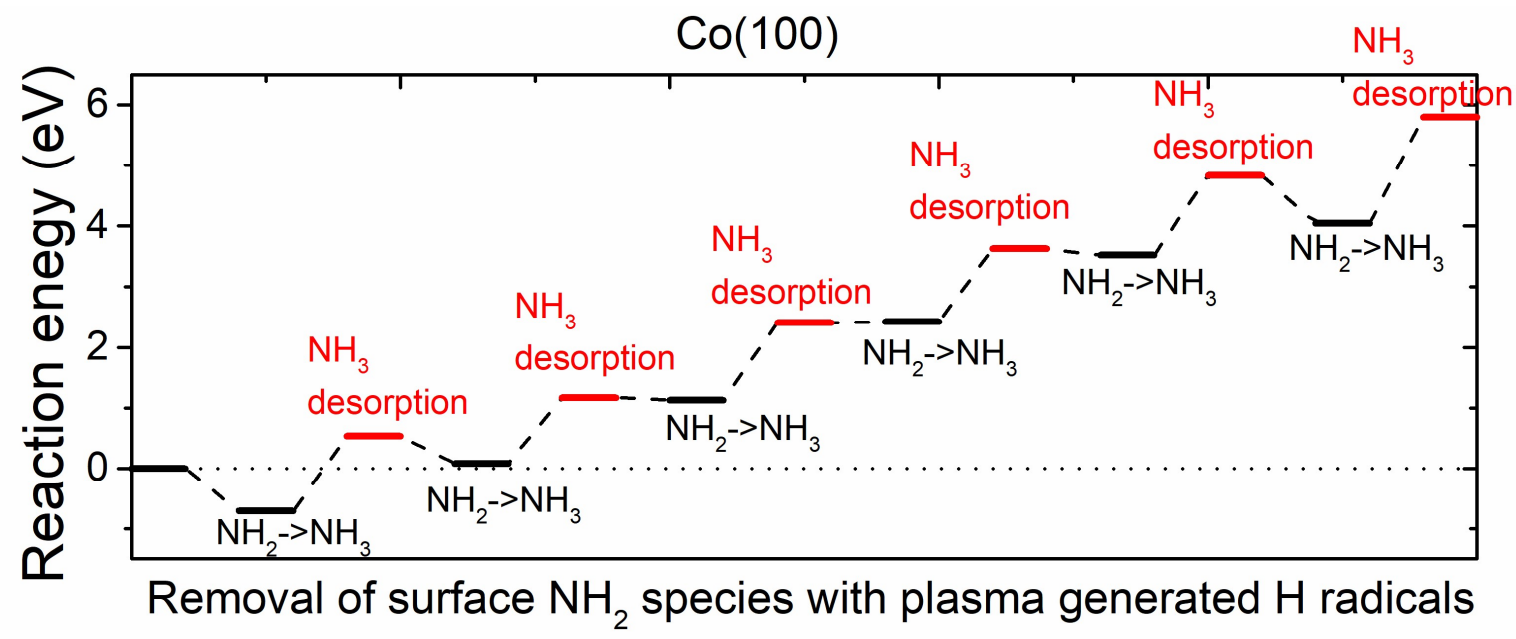

Figure 9. The plotted reaction pathway for removal of surface $\mathrm{NH}_{2}$ species with plasma generated $\mathrm{H}$ radicals on $\mathrm{NH}_{\mathrm{x}}$-terminated $\mathrm{Co}(100)$ surface.

We then performed calculations for reactions of trench $\mathrm{N}$ species and $\mathrm{H}$ radicals. The results show that trench $\mathrm{N}$ species can react with $\mathrm{H}$ radicals to form $\mathrm{NH}$, with a computed reaction energy of $0.24 \mathrm{eV}$ for the $1^{\text {st }} \mathrm{NH}$ formation. However, there are no further reactions to form intermediate $\mathrm{NH}_{2}$ or by-product $\mathrm{NH}_{3}$. Instead, the next $\mathrm{H}$ radicals prefer to react with another trench $\mathrm{N}$ species to form NH. The plotted reaction pathway for trench $\mathrm{NH}$ formation is shown in Figure 10. The 
computed reaction energies are overall negative, except for a small energy cost for the formation of the first NH. The configurations of structures along the reaction pathway are shown in Figure S10. We note that for the $6^{\text {th }} \mathrm{H}$ radical, it would prefer to bind to surface Co atoms rather than recover the $6^{\text {th }} \mathrm{N}$ to $\mathrm{NH}$ species. Thus, for trench $\mathrm{N}$ species, at the plasma step with $\mathrm{H}$ radicals, at most five $\mathrm{N}$ species can recover to $\mathrm{NH}$. These results indicate the difficulty in eliminating $\mathrm{N}$ species from the Co (100) surface via ammonia formation.

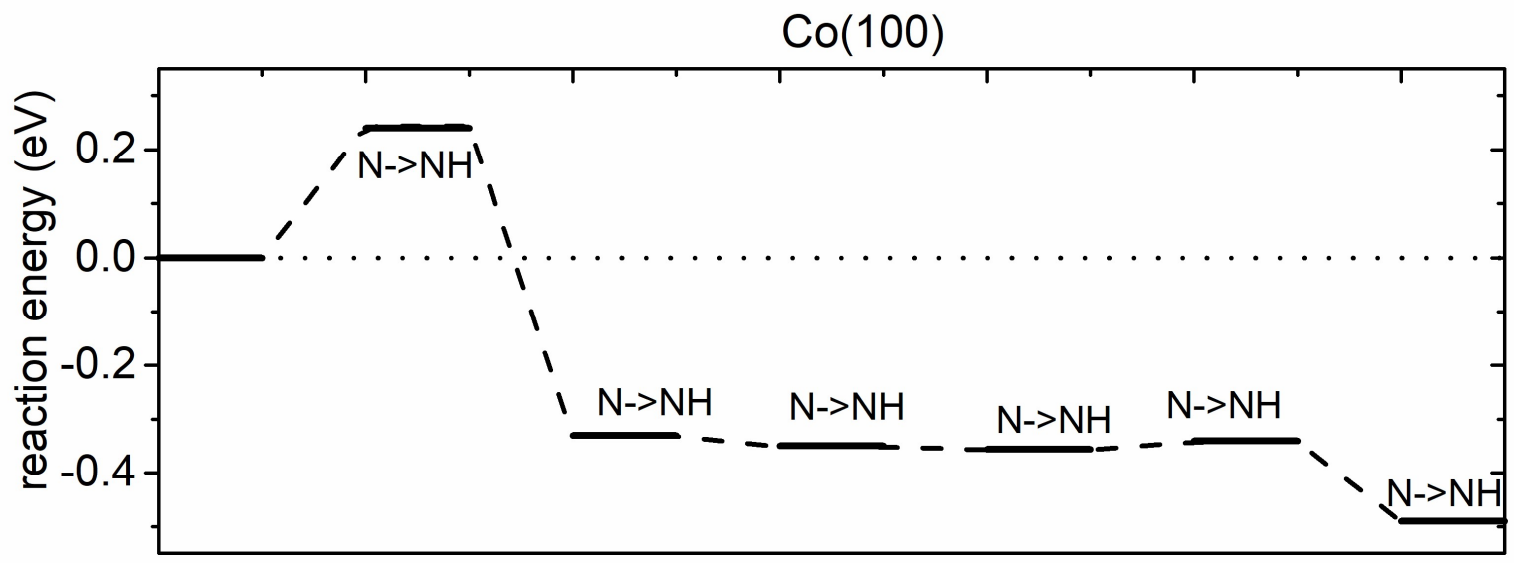

Trench $\mathrm{N}$ atoms react with plasma generated $\mathrm{H}$ radicals to form $\mathrm{NH}$

Figure 10. The plotted reaction pathway for trench $\mathrm{N}$ atoms recover to $\mathrm{NH}$ with plasma generated $\mathrm{H}$ radicals on $\mathrm{NH}_{\mathrm{x}}$-terminated $\mathrm{Co}(100)$ surface.

Given the difficulty in eliminating surface $\mathrm{NH}_{2}$ and trench $\mathrm{N}$ via $\mathrm{NH}_{3}$ formation and desorption, we have computed the reaction energies for the formation of hydrazine $\left(\mathrm{N}_{2} \mathrm{H}_{4}\right)$ and diazene $\left(\mathrm{N}_{2} \mathrm{H}_{2}\right)$ that are formed through the interaction with $\mathrm{NH}$ and $\mathrm{NH}_{2}$ radicals. After static DFT relaxations, hydrazine or diazene dissociate into two $\mathrm{NH}_{2}$ or two $\mathrm{NH}$ that are bound to the Co (100) surface, indicating the unfavourable formation of hydrazine and diazene.

To summarise, on the $\mathrm{Co}(100)$ surface, the removal of surface $\mathrm{NH}_{\mathrm{x}}$ species as ammonia is endothermic, while it is an exothermic reaction on the $\mathrm{Co}(001)$ surface. Instead, on $\mathrm{Co}(100)$, 
plasma generated $\mathrm{H}$ radicals react with trench $\mathrm{N}$ species to form stable $\mathrm{NH}$ species, which are then available for the next hydrogen transfer step in the next metal precursor pulse.

3.4 Ab initio molecular dynamics simulations of the reaction of plasma radicals at Co (001) and (100) surfaces

On $\mathrm{Co}(001)$ surface, ab initio molecular dynamics (AIMD) calculations were performed by introducing $9 \mathrm{H}$ radicals at a temperature of $600 \mathrm{~K}$. We form pyridine through $\mathrm{N}$ radical insertion, at a coverage of 3.03 pyridine $/ \mathrm{nm}^{2}$. The time step is $1.5 \mathrm{fs}$, with total running time at $2.25 \mathrm{ps}$ with the NVT (canonical) ensemble. The structures at the end of the MD simulations are shown in Figure 11 and a movie of the simulation is shown in the supporting information. Over half of $\mathrm{H}$ radicals recombine to form $\mathrm{H}_{2}$ molecules, which is first observed at 0.21 ps (Fig. S11(a)). Some $\mathrm{H}$ radicals contribute to $\mathrm{NH}_{3}$ formation at 0.33 ps (Fig. $\mathrm{S} 11$ (b)) and pyridinium formation at $1.26 \mathrm{ps}$ (Fig. S11(c)). Thus, upon introducing $9 \mathrm{H}$ radicals on $\mathrm{Co}(001)$ surface with surface bound pyridine at a coverage of 3.03 pyridine $/ \mathrm{nm}^{2}$, the MD results indicate that surface $\mathrm{NH}_{\mathrm{x}}$ species can be eliminated via $\mathrm{NH}_{3}$ formation and desorption while surface bound pyridine is eliminated via either direct desorption or pyridinium formation and desorption. These results are consistent with the static DFT calculations in section 3.1 and 3.2. 
(a)

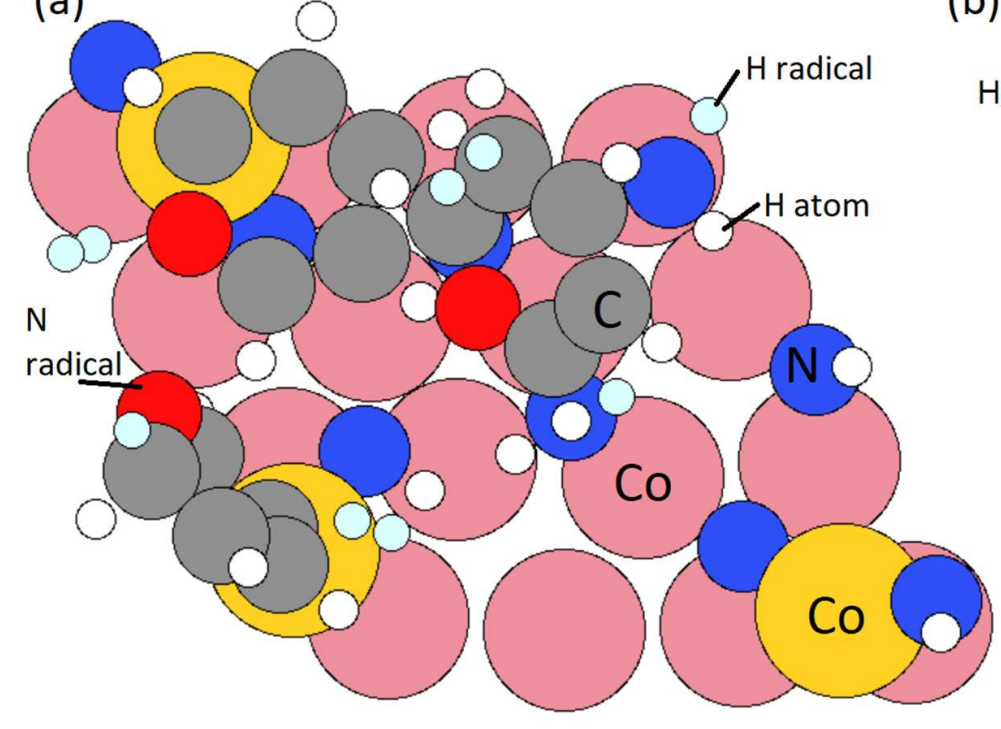

top view (b)
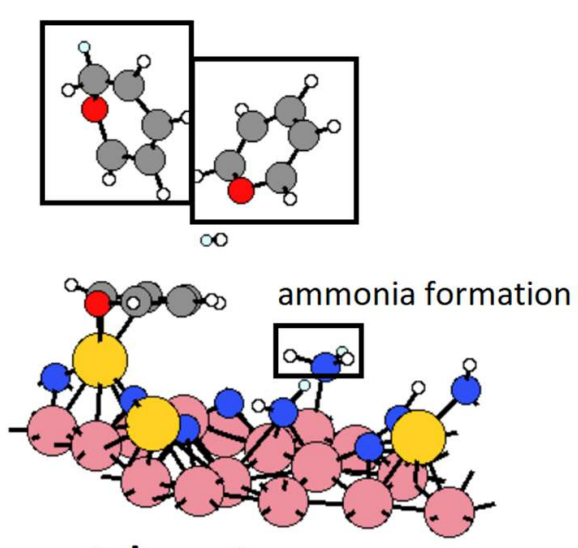

side view

Figure 11. The structure snapshot at the end of the $\mathrm{MD}$ calculation at $600 \mathrm{~K}$ on the $\mathrm{NH}_{\mathrm{x}}$-terminated $\mathrm{Co}(001)$ surface with $9 \mathrm{H}$ radicals in (a) top view, and (b) side view. Carbon, nitrogen, and hydrogen atoms are presented by grey, blue, and white colour. $\mathrm{H}$ radicals are represented by light blue sphere. Substrate Co and $\mathrm{Co}$ from $\mathrm{CoCp}_{2}$ are represented by orange and yellow spheres, respectively. $\mathrm{H}$ and $\mathrm{N}$ radicals are represented by light blue and red spheres, respectively.

To explore the dynamics on the $\mathrm{Co}(100)$ surface, $\mathrm{MD}$ calculations are performed on the $\mathrm{NH}_{\mathrm{x}}{ }^{-}$ terminated $\mathrm{Co}(100)$ surface with six deposited Co atoms on the surface at temperatures of $600 \mathrm{~K}$ and $1000 \mathrm{~K}$. The time step is $1.5 \mathrm{fs}$ with total simulation time of $2.25 \mathrm{ps}$ with the NVT ensemble. The structures at the end of this MD simulation are shown in Figure 12. For $\mathrm{T}=600 \mathrm{~K}$ and $1000 \mathrm{~K}$, there is no desorption of surface $\mathrm{NH}_{\mathrm{x}}$ terminations indicating that the removal of these surface bound $\mathrm{NH}_{\mathrm{x}}$ species requires a high energy cost. This is in line with the static DFT results of computed endothermic reactions of eliminating surface $\mathrm{NH}_{\mathrm{x}}$ species with $\mathrm{H}$ radicals. For $\mathrm{T}=1000 \mathrm{~K}$, we see that the deposited surface Co atoms migrates to form small Co nanoclusters due to trench $\mathrm{N}$ migrating to surface sites. 
(a)

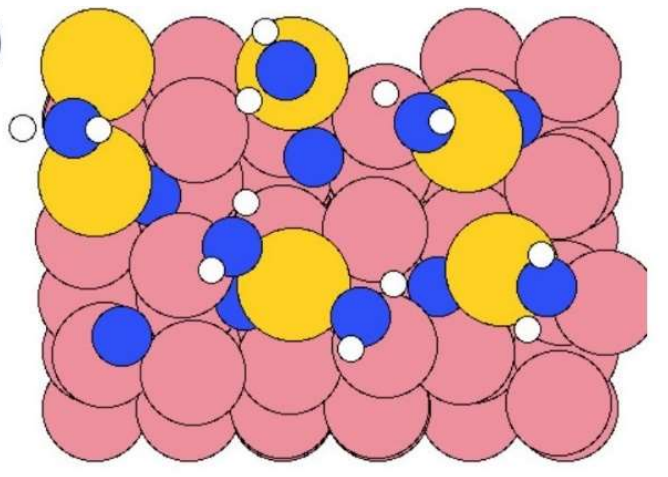

(b)

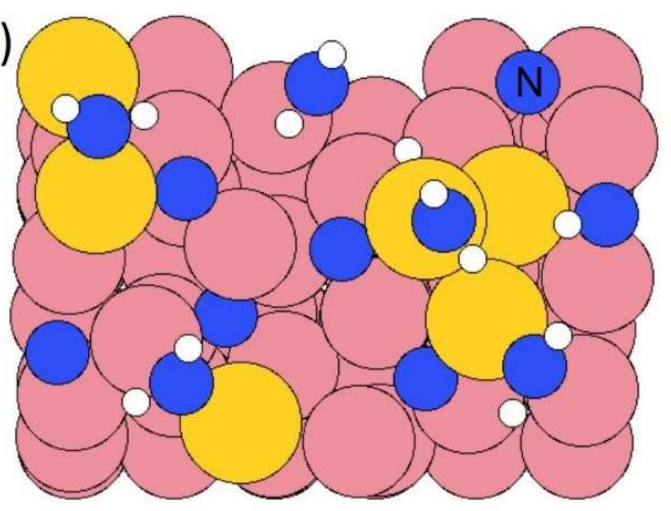

top view

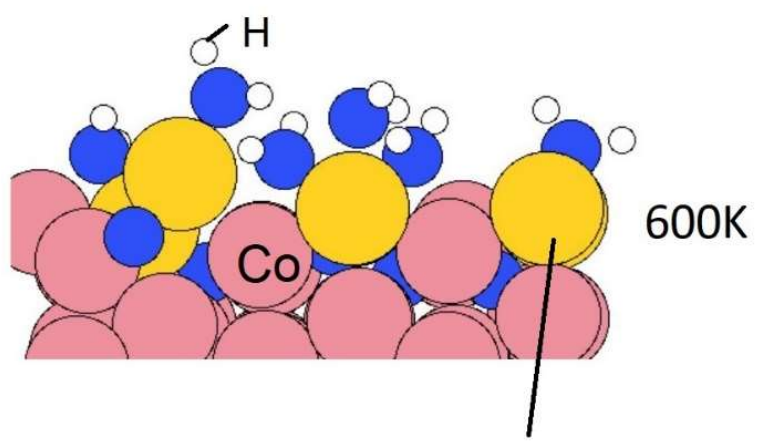

Co from metal precursor $\mathrm{CoCp}_{2}$

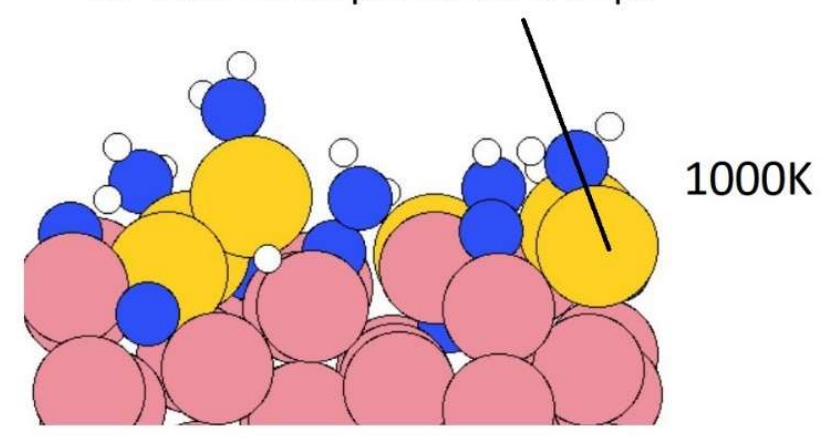

side view

time step at $1.5 \mathrm{fs}$, total running time at $2.25 \mathrm{ps}$

Figure 12. The configurations of resulting structures after MD calculations at (a) $600 \mathrm{~K}$, and (b) $1000 \mathrm{~K}$ on $\mathrm{NH}_{\mathrm{x}}$-terminated $\mathrm{Co}(100)$ surface with six deposited Co atoms on the surface. Carbon, nitrogen, and hydrogen atoms are presented by grey, blue, and white colour. Substrate Co and Co from $\mathrm{CoCp}_{2}$ are represented by orange and red spheres, respectively.

\section{Discussion}

\subsection{Structures of N-plasma treated Co (001) and (100) surfaces}

On the low energy $\mathrm{Co}(001)$ surface, during the plasma cycle the $\mathrm{Cp}$ ligand and surface $\mathrm{NH}_{\mathrm{x}}$ species are eliminated by plasma generated $\mathrm{N}$ and $\mathrm{H}$ radicals, resulting in Co atoms deposited on the $\mathrm{Co}(001)$ surface at a coverage of $3.03 \mathrm{Co} / \mathrm{nm}^{2}$. On the $\mathrm{Co}(100)$ surface, the surface $\mathrm{NH}_{2}$ species cannot be eliminated with $\mathrm{H}$ radicals since these reactions are endothermic. The trench $\mathrm{N}$ species 
will transform to $\mathrm{NH}$ after interaction with $\mathrm{H}$ radicals. These trench $\mathrm{N}$ species on $\mathrm{Co}(100)$ surface will be a potential source of $\mathrm{N}$ impurities in deposited Co thin films. ${ }^{30,42}$

We applied Bader charge analysis to the $\mathrm{Co}(001)$ and (100) surfaces in each step of $\mathrm{NH}_{\mathrm{x}}$ removal. The results are summarized in Table 3. On the $\mathrm{Co}(001)$ surface, the $\mathrm{Cp}$ ligands have been removed prior to the interaction of surface $\mathrm{NH}$ species with $\mathrm{N}$ radicals. The computed transferred charges for the formation of the ammonia by-product are almost the same at a value of $c a \cdot-0.10 \mathrm{e}^{-}$on $\mathrm{NH}_{\mathrm{x}^{-}}$ terminated $\mathrm{Co}(001)$ surface. However, on $\mathrm{NH}_{\mathrm{x}}$-terminated $\mathrm{Co}(100)$ surface, the computed transferred charge from $\mathrm{NH}_{3}$ to substrate $\mathrm{Co}$ atoms at $\mathrm{NH}_{3}$ formation step increase from $0.06 \mathrm{e}^{-}$to $0.13 \mathrm{e}^{-}$along the elimination pathway. This indicates the interaction between $\mathrm{NH}_{3}$ and substrate $\mathrm{Co}$ atoms becomes stronger along the elimination pathway on $\operatorname{Co}(100)$ surface, which is in accordance with the computed positive reaction energies for $\mathrm{NH}_{3}$ formation and desorption on (100) surface.

Table 3. The computed charge transfer with Bader charge analysis, $q$ (Bader) $-q($ valence), for the elimination of surface $\mathrm{NH}_{\mathrm{x}}$ species on $3 \mathrm{CoCp}$ fragments terminated $\mathrm{Co}(001)$ surface and $\mathrm{NH}_{\mathrm{x}}$-terminated $\mathrm{Co}(100)$ surface. Noted that the $\mathrm{Cp}$ ligands are eliminated prior to surface $\mathrm{NH}$ species on $\mathrm{Co}(001)$ surface.

\begin{tabular}{cccccccccc}
\hline & $\begin{array}{c}1^{\text {st }} \mathrm{NH}_{\mathrm{x}} \\
\text { removal }\end{array}$ & $\begin{array}{c}2^{\text {nd }} \mathrm{NH}_{\mathrm{x}} \\
\text { removal }\end{array}$ & $\begin{array}{c}3^{\text {rd }} \mathrm{NH}_{\mathrm{x}} \\
\text { removal }\end{array}$ & $\begin{array}{c}4^{\text {th }} \mathrm{NH}_{\mathrm{x}} \\
\text { removal }\end{array}$ & $\begin{array}{c}5^{\text {th }} \mathrm{NH}_{\mathrm{x}} \\
\text { removal }\end{array}$ & $\begin{array}{c}6^{\text {th }} \mathrm{NH}_{\mathrm{x}} \\
\text { removal }\end{array}$ & $\begin{array}{c}7^{\text {th }} \mathrm{NH}_{\mathrm{x}} \\
\text { removal }\end{array}$ & $\begin{array}{c}8^{\text {th }} \mathrm{NH}_{\mathrm{x}} \\
\text { removal }\end{array}$ & $\begin{array}{c}9^{\text {th }} \mathrm{NH}_{\mathrm{x}} \\
\text { removal }\end{array}$ \\
\hline $\mathrm{No}(001)$ & $-0.08 \mathrm{e}^{-}$ & $-0.11 \mathrm{e}^{-}$ & $-0.10 \mathrm{e}^{-}$ & $-0.09 \mathrm{e}^{-}$ & $-0.10 \mathrm{e}^{-}$ & $-0.10 \mathrm{e}^{-}$ & $-0.07 \mathrm{e}^{-}$ & $-0.08 \mathrm{e}^{-}$ & $-0.08 \mathrm{e}^{-}$ \\
\hline $\mathrm{Co}(100)$ & $-0.05 \mathrm{e}^{-}$ & $-0.06 \mathrm{e}^{-}$ & $-0.06 \mathrm{e}^{-}$ & $-0.08 \mathrm{e}^{-}$ & $-0.11 \mathrm{e}^{-}$ & $-0.13 \mathrm{e}^{-}$ & - & - & - \\
\hline
\end{tabular}

On Co(001) surface, after few cycles, a full layer Co atoms will be deposited on the surface and surface $\mathrm{NH}_{\mathrm{x}}$ species are completely removed at the plasma cycle. Whereas, on $\mathrm{Co}(100)$ surface, the $\mathrm{NH}_{\mathrm{x}}$ species cannot be completely eliminated. We have examined a full layer of Co atoms 
(1ML, in total 9 Co atoms) deposited on the Co(100) surface and this is shown in Figure 13(a). The initial surface Co atoms become trench Co atoms and the deposited Co atoms become new surface Co atoms. From our previous thermodynamics study on $\mathrm{NH}_{\mathrm{x}}$-terminated Co surfaces, $\mathrm{NH}_{2}$ prefers surface bridge site and NH prefers trench bridge site. ${ }^{31}$ With this in mind, we have performed calculations of surface rearrangement on $\mathrm{NH}_{\mathrm{x}}$-terminated $\mathrm{Co}(100)$ surface with a full layer of deposited Co atoms. The relaxed structure is shown in Figure 13(b). This surface $\mathrm{NH}_{\mathrm{x}}$ rearrangement is exothermic with a negative energy gain at the value of $-0.48 \mathrm{eV}$. After rearrangement, $\mathrm{NH}_{2}$ binds to surface bridge sites.

(a)
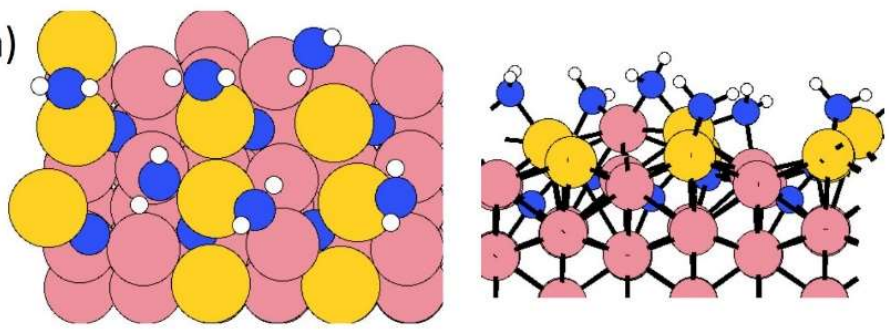

Reference energy $\mathrm{E}=0 \mathrm{eV}$

$\mathrm{NH}_{\mathrm{x}}$-terminated $\mathrm{Co}(100)$ with one full layer deposited Co atoms

(b)

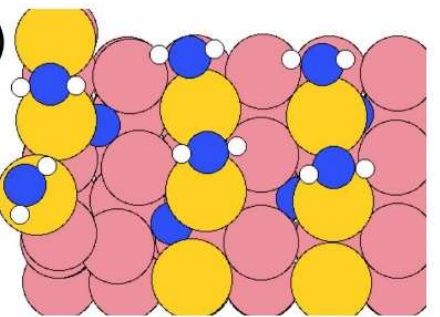

top view

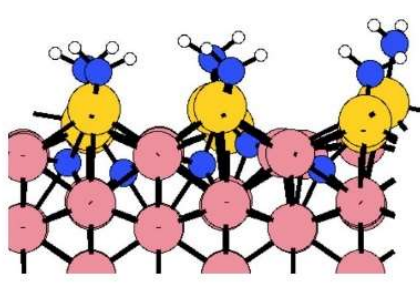

side view

Figure 13. The top view and side view of (a) relaxed original structure, and (b) structure after surface $\mathrm{NH}_{\mathrm{x}}$ rearrangement on $\mathrm{NH}_{\mathrm{x}}$-terminated $\mathrm{Co}(100)$ with one full layer deposited Co atoms. Carbon, nitrogen, and hydrogen atoms are presented by grey, blue, and white colour. Substrate Co and Co from $\mathrm{CoCp}_{2}$ are represented by orange and red spheres, respectively.

\subsection{Regeneration of surface $\mathrm{NH}_{x}$ Terminations}


If we consider the next ALD cycle, at the post-plasma stage, the metal surface is supposed to be terminated with $\mathrm{NH}_{\mathrm{x}}$ species before the next metal precursor half-reaction, analogous to the regeneration of hydroxyl groups in thermal or plasma assisted metal oxide ALD. ${ }^{43-44}$ To explore how this surface can form, we have performed MD calculations at $600 \mathrm{~K}$ for the interaction of $\mathrm{NH}$ radicals with the $\mathrm{Co}(001)$ surface, where Co atoms were deposited at a coverage of $3.03 \mathrm{Co} / \mathrm{nm}^{2}$ and the original surface NH species were eliminated as ammonia. Two coverages of NH radicals are explored, i.e. $0.67 \mathrm{ML}$ (in total $6 \mathrm{NH}$ ) and $0.89 \mathrm{ML}$ (in total $8 \mathrm{NH})$ on $(3 \times 3)$ supercell $(1 \mathrm{ML}$ corresponds to $9 \mathrm{NH}$ radicals). The time step is $1.5 \mathrm{fs}$ with a simulation time of $2.25 \mathrm{ps}$ in the NVT ensemble. The structures at the two coverages of $\mathrm{NH}$ radicals after MD calculations are shown in Figure 14.

(a)

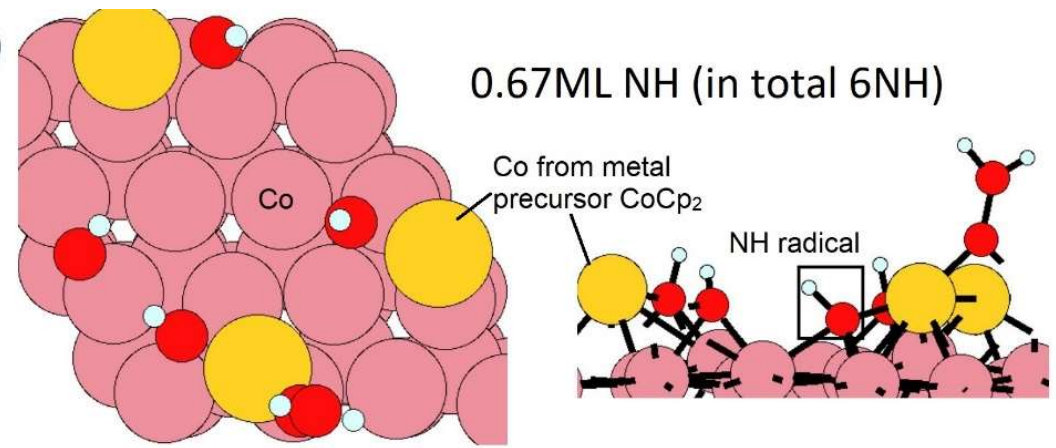

(b)

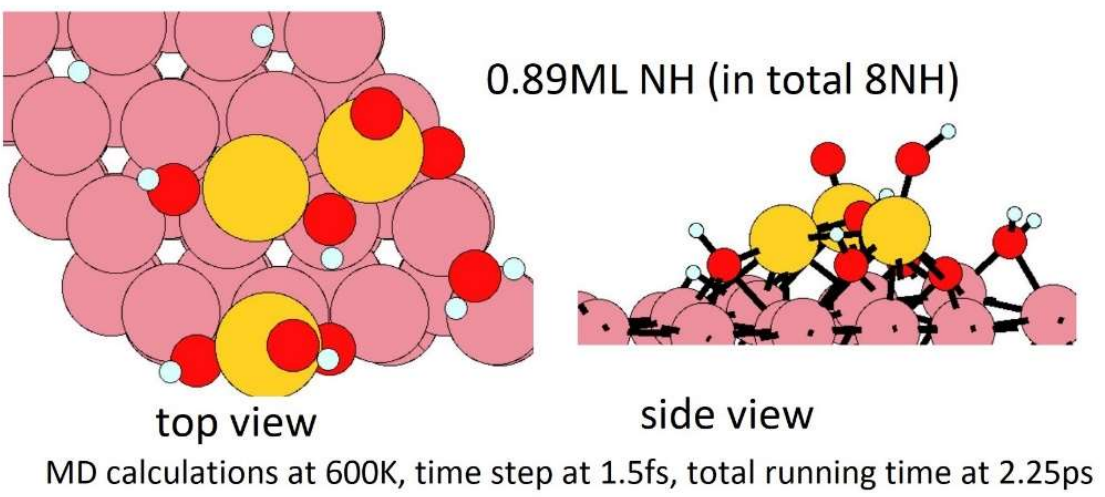

Figure 14. The configurations of structures after MD calculations on Co(001) surface with NH radicals at the coverage of (a) $0.67 \mathrm{ML}$, and (b) $0.89 \mathrm{ML}$. Carbon, nitrogen, and hydrogen atoms are presented by grey, blue, and white colour. Substrate Co and Co from $\mathrm{CoCp}_{2}$ are represented by orange and yellow spheres, respectively. Plasma generated $\mathrm{N}$ and $\mathrm{H}$ radicals are represented red and light blue spheres, respectively. 
From these simulations, the $\operatorname{Co}(001)$ surface is covered with $\mathrm{NH}$ terminations at a coverage of $0.44 \mathrm{ML}$ ( $4 \mathrm{NH}$ on the surface). This coverage is slightly lower than the determined stable coverage of $\mathrm{NH}$ terminations on $\mathrm{Co}(001)$ surface from our previous study ${ }^{31}$, which is $0.56 \mathrm{ML}$ (5NH on the surface). At an initial higher coverage of $0.89 \mathrm{ML} \mathrm{NH}$, we observe formation of surface bound $\mathrm{NH}$ and $\mathrm{NH}_{2}$ species, as well as surface bound $\mathrm{H}$ species and $\mathrm{N}$ species, which form as a result of the dissociation of NH radicals under these simulation conditions. We can infer that at the post-plasma stage, $\mathrm{NH}$ radicals contribute to the formation of the $\mathrm{NH}_{\mathrm{x}}$-terminations on the metal surface, which then contributes in the $\mathrm{Cp}$ ligand elimination in the next metal precursor pulse. Hydrogen alone cannot produce the reactive $\mathrm{NH}$ species; although $\mathrm{N}_{2}$ alone would promote $\mathrm{Cp}$ ligand elimination via pyridine formation, these $\mathrm{N}$ radicals cannot produce reactive $\mathrm{NH}$ surface termination. Thus, the plasma deposition of Co requires both hydrogen and nitrogen/ammonia plasma.

Then, we perform MD calculations at $600 \mathrm{~K}$ to explore how $\mathrm{NH}_{\mathrm{x}}$-terminations are formed on $\mathrm{Co}(100)$ surface at the post-plasma stage. The $\mathrm{Co}(100)$ surface after $\mathrm{NH}_{\mathrm{x}}$ rearrangement (Figure $14(\mathrm{~b})$ ) is chosen to be the substrate. The coverage of $\mathrm{NH}$ radicals is $0.67 \mathrm{ML}$ (in total $6 \mathrm{NH}$ ), which are previously determined as the saturation coverage of trench NH species at ALD deposition temperature. ${ }^{31}$ The time step is $1.5 \mathrm{fs}$ with a simulation time of $2.25 \mathrm{ps}$ with the NVT (or canonical) ensemble. The initial structure and final structure are shown in Figure 15. By-products $\mathrm{NH}_{3}$ and $\mathrm{N}_{2}$ are formed and released, resulting in surface terminations including surface bound $\mathrm{N}$, surface bound $\mathrm{NH}_{2}$, and trench $\mathrm{NH}$ species. The original trench $\mathrm{N}$ atoms are now incorporated into the subsurface layer. One full layer of Co atoms is deposited and the terminations after the post-plasma stage are $\mathrm{NH}_{\mathrm{x}}$-terminations with $4 \mathrm{NH}_{2}+4 \mathrm{NH}$ on $\mathrm{Co}(100)$ surface. This coverage is slightly lower 
than the determined stable coverage of mixed terminations on Co (100) surface from our previous study ${ }^{31}$, which is $6 \mathrm{NH}+6 \mathrm{NH}_{2}$ on the surface.

(a)

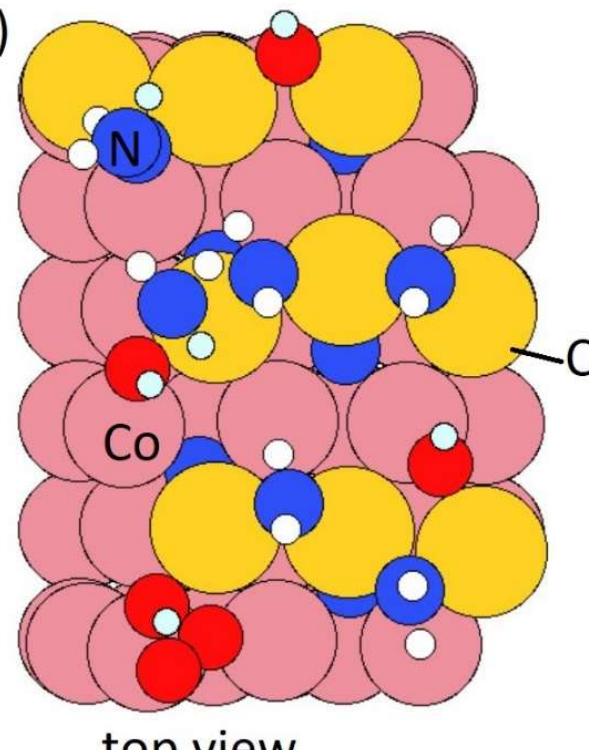

top view (b)

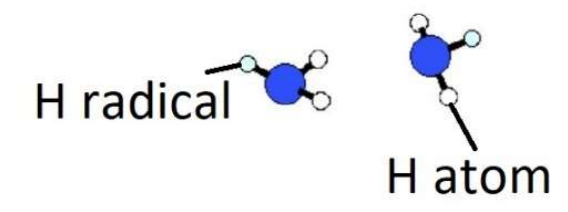

QN radical

from $\mathrm{CoCp}_{2}$

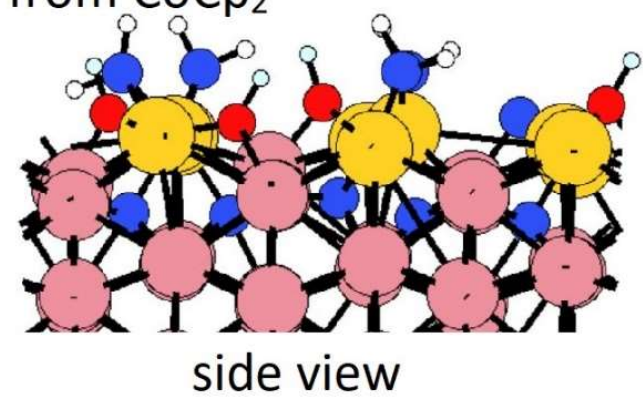

side view

\section{MD calculations at $600 \mathrm{~K}$, time step at $1.5 \mathrm{fs}$, total running time at $2.25 \mathrm{ps}$}

Figure 15. The configurations of (a) initial structure, and (b) final structure for MD calculations on the structure after surface rearrangement and $\mathrm{NH}$ radicals. Carbon, nitrogen, and hydrogen atoms are presented by grey, blue, and white colour. Substrate $\mathrm{Co}$ and $\mathrm{Co}$ from $\mathrm{CoCp}_{2}$ are represented by orange and yellow spheres, respectively. Plasma generated $\mathrm{N}$ and $\mathrm{H}$ radicals are represented red and light blue spheres, respectively.

It is noted that the trench $\mathrm{N}$ species are present throughout the deposition process and cannot be removed completely in either the metal precursor or plasma cycle. We can infer that the $\mathrm{N}$ impurities exists with the possibility of formation of $\mathrm{Co}_{x} \mathrm{~N}$. This is consistent with the reported nitrogen incorporation into deposited Co thin films and Cobalt nitride using $\mathrm{CoCp}_{2}$ and $\mathrm{NH}_{3}$ plasma. $^{30,42}$ At temperatures of $533 \mathrm{~K}$ and below, the deposited thin films consist primarily of $\mathrm{Co}_{2} \mathrm{~N}$. At higher temperature at $573 \mathrm{~K}$, the $\mathrm{Co}_{x} \mathrm{~N}$ is a mixture of $\mathrm{Co}_{3} \mathrm{~N}$ and Co. Finally, if the 
temperature is up to $623 \mathrm{~K}$, the deposited thin film is nominally pure $\mathrm{Co}$, which is due to the decomposition of Cobalt nitride. ${ }^{30}$ Detailed studies are needed to study the formation of surface cobalt nitride and removal of these $\mathrm{N}$ species, which is out of the scope of current paper.

\section{Conclusions}

We have presented a detailed first principles study of the chemistry of the plasma pulse in hydrogen/nitrogen plasma enhanced ALD of Co metal. We begin with a surface after the metal precursor pulse, with CoCp fragment terminated Co (001) surface at a coverage of $3.03 \mathrm{CoCp} / \mathrm{nm}^{2}$ and an $\mathrm{NH}_{\mathrm{x}}$-terminated $\mathrm{Co}(100)$ surface with deposited Co atoms at a coverage of $3.33 \mathrm{Co} / \mathrm{nm}^{2}$. This work focuses on the reaction mechanism in plasma cycle of plasma radicals and Co (001) and (100) surfaces terminated with $\mathrm{Cp}$ ligand (if any) and $\mathrm{NH}_{\mathrm{x}}$ species in atomic scale.

On $\mathrm{Co}(001)$ surface, the preferred reaction mechanism is that $\mathrm{Cp}$ ligand is eliminated prior to surface $\mathrm{NH}_{\mathrm{x}}$ species via pyridine formation and desorption with plasma generated $\mathrm{N}$ radicals. Bader charge analysis indicates that for the ammonia desorption step, $\mathrm{Cp}$ ligand eliminated prior to $\mathrm{NH}_{\mathrm{x}}$ elimination has less transferred charge between $\mathrm{NH}_{3}$ and substrate $\mathrm{Co}$, compared to $\mathrm{Cp}$ ligand present throughout. The surface NH species and N species are eliminated via intermedia $\mathrm{NH}$ formation, $\mathrm{NH}_{2}$ formation, by-product $\mathrm{NH}_{3}$ formation and desorption. The reactions of $\mathrm{Cp}$ ligand removal and subsequent $\mathrm{NH}_{\mathrm{x}}$ removal are overall exothermic, which are completely eliminated on $\operatorname{Co}(001)$ surface, resulting deposited Co atoms on (001) surface at a coverage of $3.03 \mathrm{Co} / \mathrm{nm}^{2}$.

There is a different behaviour on the $\mathrm{Co}(100)$ surface. The surface $\mathrm{NH}_{2}$ species cannot be completely removed with $\mathrm{H}$ radicals via $\mathrm{NH}_{3}$ formation and desorption due to an overall endothermic reaction emergy. Instead, $\mathrm{H}$ radicals will contribute to reform trench $\mathrm{NH}$ species with 
computed negative reaction energies. When a full layer of Co atoms are deposited on $\operatorname{Co}(100)$ surface, due to its unique zigzag structure, the original surface Co atoms become trench Co and the deposited Co atoms occupy the surface site. However, these trench $\mathrm{N}$ species are present throughout the deposition process and result in formation of $\mathrm{Co}_{\mathrm{x}} \mathrm{N}$ and cannot be removed completely at the conditions of our simulations. This indicates the plasma species acting as the sources of $\mathrm{N}$ impurities in deposited Co thin films.

At the post-plasma stage, MD simulations at $600 \mathrm{~K}$ shows that $\mathrm{NH}$ radicals play an important role in regenerations of $\mathrm{NH}_{\mathrm{x}}$-terminations on $\mathrm{Co}(001)$ and (100) surfaces, which is then ready for the next metal precursor half-cycle. For Cp-based metal precursors, $\mathrm{NH}_{\mathrm{x}}$ species are required to deposit Co thin film with high purity and low resistivity, which explains why $\mathrm{NH}_{3}$ plasma or a mixture of $\mathrm{N}_{2}$ and $\mathrm{H}_{2}$ plasma are the plasma sources that work best, rather than $\mathrm{H}_{2}$ plasma or $\mathrm{N}_{2}$ plasma alone.

\section{Acknowledgements}

We acknowledge generous support from Science Foundation Ireland (SFI) through the SFI-NSFC Partnership program, Grant Number 17/NSFC/5279, NITRALD and National Natural Science Foundation of China, Grant number 51861135105. Computing resources have been generously supported by Science Foundation Ireland at Tyndall and through the SFI/HEA-funded Irish Centre for High End Computing (www.ichec.ie). J.L. acknowledges that part of the results of this research have been achieved using the DECI resource BEM cluster based in Poland at Wroclaw Centre for Networking and Supercomputing with support from the PRACE.

\section{References}

1. Tu, K., Recent Advances on Electromigration in Very-Large-Scale-Integration of Interconnects. J. Appl. Phys. 2003, 94, 5451-5473. 
2. Kondati Natarajan, S.; Nies, C.-L.; Nolan, M., Ru passivated and Ru doped $\varepsilon$-TaN surfaces as a combined barrier and liner material for copper interconnects: a first principles study. J. Mater. Chem. $C$ 2019, 7 (26), 7959-7973.

3. Greenslit, D. V.; Eisenbraun, E., Characterization of Ultrathin PEALD-Grown RuCo Films for Diffusion Barrier and Copper Direct-Plate Applications. ECS Trans. 2011, 35, 17-24.

4. Chakraborty, T.; Eisenbraun, E. T., Microstructure Analysis of Plasma Enhanced Atomic Layer Deposition-Grown Mixed-Phase RuTaN Barrier for Seedless Copper Electrodeposition. J. Vac. Sci. Technol. A 2012, 30, 020604 1-5.

5. Miikkulainen, V.; Leskelä, M.; Ritala, M.; Puurunen, R. L., Crystallinity of Inorganic Films Grown by Atomic Layer Deposition: Overview and General Trends. J. Appl. Phys. 2013, 113, 021301 1-101.

6. Johnson, R. W.; Hultqvist, A.; Bent, S. F., A Brief Review of Atomic Layer Deposition: From Fundamentals to Applications. Mater. Today 2014, 17, 236-246.

7. Kaloyeros, A. E.; Pan, Y.; Goff, J.; Arkles, B., Review-Cobalt Thin Films: Trends in Processing Technologies and Emerging Applications. ECS J. Solid State Sci. 2019, 8, P119-P152.

8. George, S. M., Atomic Layer Deposition: An Overview. Chem. Rev. 2009, 110, 111-131.

9. Profijt, H.; Potts, S.; Van de Sanden, M.; Kessels, W., Plasma-Assisted Atomic Layer Deposition: Basics, Opportunities, and Challenges. J. Vac. Sci. Technol. A 2011, 29, 050801 1-26.

10. Oviroh, P. O.; Akbarzadeh, R.; Pan, D.; Coetzee, R. A. M.; Jen, T. C., New Development of Atomic Layer Deposition: Processes, Methods and Applications. Sci. Technol. Adv. Mater. 2019, 20, 465-496.

11. Kim, H., Atomic Layer Deposition of Mmetal and Nitride Thin Films: Current Research Efforts and Applications for Semiconductor Device Processing. J. Vac. Sci. Technol. B 2003, 21, 2231-2261.

12. Knisley, T. J.; Kalutarage, L. C.; Winter, C. H., Precursors and Chemistry for The Atomic Layer Deposition of Metallic First Row Transition Metal Films. Coordin. Chem. Rev. 2013, 257, 3222-3231.

13. Kim, H., Area Selective Atomic Layer Deposition of Cobalt Thin Films. ECS Trans. 2008, 16, 219225.

14. Lim, B. S.; Rahtu, A.; Gordon, R. G., Atomic Layer Deposition of Transition Metals. Nat. Mater. 2003, 2, 749-754.

15. Kim, J.-M.; Lansalot, C.; Dussarrat, C.; Gatineau, J.; Kim, H., Plasma-enhanced atomic layer deposition of cobalt using cyclopentadienyl isopropyl acetamidinato-cobalt as a precursor. Jpn. J. Appl. Phys 2010, 49, 05FA10.

16. Kim, K.; Lee, K.; Han, S.; Jeong, W.; Jeon, H., Characteristics of Cobalt Thin Films Deposited by Remote Plasma ALD Method with Dicobalt Octacarbonyl. J. Electrochem. Soc. 2007, 154, H177-H181.

17. Kim, H., High-Quality Cobalt Thin Films by Plasma-Enhanced Atomic Layer Deposition. Electrochem. Solid-State Lett. 2006, 9, G323-G325.

18. Puurunen, R. L., Surface Chemistry of Atomic Layer Deposition: A Case Study for The Trimethylaluminum/Water Process. J. Appl. Phys. 2005, 97, 121301 1-52.

19. Elliott, S.; Scarel, G.; Wiemer, C.; Fanciulli, M.; Pavia, G., Ozone-Based Atomic Layer Deposition of Alumina from TMA: Growth, Morphology, and Reaction Mechanism. Chem. Mater. 2006, 18, 3764-3773. 20. Weckman, T.; Laasonen, K., First Principles Study of The Atomic Layer Deposition of Alumina by TMA-H $\mathrm{H}_{2} \mathrm{O}$-Process. Phys. Chem. Chem. Phys. 2015, 17, 17322-17334.

21. Weckman, T.; Laasonen, K., Atomic Layer Deposition of Zinc Oxide: Diethyl Zinc Reactions and Surface Saturation from First-Principles. J. Phys. Chem. C 2016, 120 (38), 21460-21471.

22. Lee, S.-J.; Kim, S.-H.; Saito, M.; Suzuki, K.; Nabeya, S.; Lee, J.; Kim, S.; Yeom, S.; Lee, D.-J., PlasmaFree Atomic Layer Deposition of Ru Thin Films Using $\mathrm{H}_{2}$ Molecules as A Nonoxidizing Reactant. J. Vac. Sci. Technol. A 2016, 34 (3), 031509.

23. Zhu, B.; Ding, Z.-J.; Wu, X.; Liu, W.-J.; Zhang, D. W.; Ding, S.-J., Plasma-Enhanced Atomic Layer Deposition of Cobalt Films Using Co(EtCp $)_{2}$ as A Metal Precursor. Nanoscale Res. Lett. 2019, 14, 76 1-7. 
24. Kim, H.; Oh, I.-K., Review of plasma-enhanced atomic layer deposition: Technical enabler of nanoscale device fabrication. Jpn. J. Appl. Phys 2014, 53 (3S2), 03 DA01.

25. Rossnagel, S.; Sherman, A.; Turner, F., Plasma-enhanced atomic layer deposition of Ta and Ti for interconnect diffusion barriers. J. Vac. Sci. Technol. B 2000, 18, 2016-2020.

26. Yoon, J.; Kim, D.; Cheon, T.; Kim, S.-H.; Kim, H., Atomic Layer Deposition of Co Using $\mathrm{N}_{2} / \mathrm{H}_{2}$ Plasma as A Reactant. J. Electrochem. Soc. 2011, 158, H1179-H1182.

27. Vos, M. F.; van Straaten, G.; Kessels, W. E.; Mackus, A. J., Atomic Layer Deposition of Cobalt Using $\mathrm{H}_{2^{-}}, \mathrm{N}_{2^{-}}$, and $\mathrm{NH}_{3}$-Based Plasmas: On the Role of the Co-reactant. J. Phys. Chem. C 2018, 122, 22519-22529. 28. Nolan, M.; Elliott, S. D., Competing Mechanisms in Atomic Layer Deposition of $\mathrm{Er}_{2} \mathrm{O}_{3}$ versus $\mathrm{La}_{2} \mathrm{O}_{3}$ from Cyclopentadienyl Precursors. Chem. Mater. 2010, 22, 117-129.

29. Rai, V. R.; Vandalon, V.; Agarwal, S., Surface Reaction Mechanisms During Ozone and Oxygen Plasma Assisted Atomic Layer Deposition of Aluminum Oxide. Langmuir 2010, 26, 13732-13735.

30. van Straaten, G.; Deckers, R.; Vos, M. F.; Kessels, W. M.; Creatore, M., Plasma-Enhanced Atomic Layer Deposition of Cobalt and Cobalt Nitride: What Controls the Incorporation of Nitrogen? J. Phys. Chem. C. 2020, 124, 22046-22054.

31. Liu, J.; Nolan, M., Coverage and Stability of NHx-Terminated Cobalt and Ruthenium Surfaces: A First-Principles Investigation. J. Phys. Chem. C 2019, 123, 25166-25175.

32. Liu, J.; Lu, H.; Zhang, D. W.; Nolan, M., Reaction Mechanism of the Metal Precursor Pulse in Plasma-Enhanced Atomic Layer Deposition of Cobalt and the Role of Surface Facets. The Journal of Physical Chemistry C 2020, 124 (J. Phys. Chem. C), 11990-12000.

33. Kresse, G.; Joubert, D., From Ultrasoft Pseudopotentials to The Projector Augmented-wave Method. Phys. Rev. B 1999, 59, 1758-1775.

34. Kresse, G.; Hafner, J., Ab initio molecular-dynamics simulation of the liquid-metal-amorphoussemiconductor transition in germanium. Phys. Rev. B 1994, 49, 14251.

35. Perdew, J. P.; Chevary, J. A.; Vosko, S. H.; Jackson, K. A.; Pederson, M. R.; Singh, D. J.; Fiolhais, C., Atoms, Molecules, Solids, and Surfaces: Applications of The Generalized Gradient Approximation for Exchange and Correlation. Phys. Rev. B 1992, 46, 6671-6687.

36. Perdew, J. P.; Burke, K.; Ernzerhof, M., Generalized Gradient Approximation Made Simple. Phys. Rev. Lett. 1996, 77, 3865-3868.

37. Monkhorst, H. J.; Pack, J. D., Special Points for Brillouin-zone Integrations. Phys. Rev. B 1976, 13, 5188-5192.

38. Maimaiti, Y.; Elliott, S. D., Precursor Adsorption on Copper Surfaces as the First Step during the Deposition of Copper: A Density Functional Study with van der Waals Correction. J. Phys. Chem. C 2015, 119, 9375-9385.

39. Yu, M.; Trinkle, D. R., Accurate and efficient algorithm for Bader charge integration. J. Chem. Phys. 2011, 134, 064111.

40. Tang, W.; Sanville, E.; Henkelman, G., A grid-based Bader analysis algorithm without lattice bias. J. Condens. Matter Phys. 2009, 21, 084204.

41. Shirazi, M.; Elliott, S. D., Cooperation between adsorbates accounts for the activation of atomic layer deposition reactions. Nanoscale 2015, 7, 6311-6318.

42. Reif, J.; Knaut, M.; Killge, S.; Winkler, F.; Albert, M.; Bartha, J. W., In Vacuo Studies on PlasmaEnhanced Atomic Layer Deposition of Cobalt Thin Films. J. Vac. Sci. Technol. A 2020, 38, 012405 1-9.

43. Van Hemmen, J.; Heil, S.; Klootwijk, J.; Roozeboom, F.; Hodson, C.; Van de Sanden, M.; Kessels, W., Plasma and Thermal ALD of Al2O3 in a Commercial 200 mm ALD Reactor. J. Electrochem. Soc. 2007, $154, \mathrm{G} 165$.

44. Fomengia, G. N.; Nolan, M.; Elliott, S. D., First principles mechanistic study of self-limiting oxidative adsorption of remote oxygen plasma during the atomic layer deposition of alumina. Phys. Chem. Chem. Phys. . 2018, 20, 22783-22795. 
